\title{
Epilepsy and Neurocysticercosis in Sub-Saharan Africa
}

\author{
Andrea Sylvia Winkler
}

Additional information is available at the end of the chapter

http://dx.doi.org/10.5772/53289

\section{Introduction}

In sub-Saharan Africa neurocysticercosis (NCC), which represents the infection of a human brain with the larva (=cysticercus) of the pork tapeworm (=Taenia solium), and epilepsy due to various causes are among the most frequent neurological disorders/syndromes. To date, NCC in the context of sub-Saharan Africa has not attracted much attention despite the fact that the prevalence rates of human and porcine cysticercosis seem to increase and both diseases are treatable. Epilepsy represents the most common neurological disorder in many parts of sub-Saharan Africa and NCC seems to be a major cause of it in Taenia solium cysticercosis endemic areas. Diagnosing NCC among people with epilepsy is vital as this not only prevents further morbidity and mortality through potential aggravation of the disease, but also leads to a different treatment approach: from a mere symptomatic treatment with administration of antiepileptic medication only to a curative approach, assuming that once the parasite has been cleared epileptic seizures will cease. However, in the diagnosis and treatment of NCC neuroimaging plays a crucial role and this has to be considered when dealing with affected individuals form resource-poor settings, where neuroimaging is not available. Therefore special diagnostic and therapeutic guidelines for sub-Saharan Africa have to be developed, but so far national and international stakeholders have not taken this into consideration. This chapter aims at raising awareness of both NCC and epilepsy in subSaharan African, appealing to the international community to consider NCC in resourcepoor settings as a separate entity regarding its diagnostic and therapeutic approach with the need for clearly defined guidelines in the described context.

\subsection{Definition of epilepsy and acute symptomatic epileptic seizures}

A condition characterized by recurrent (two or more) afebrile epileptic seizures that is unprovoked by any immediate identified cause and thus is not due to an acute intracranial or extracranial condition is termed epilepsy [1]. A person who has had a seizure within the 
last five years and those on anticonvulsant medication are considered to have "active epilepsy" [1,2]. The definition of active epilepsy does not have implications on starting antiepileptic treatment. Some African researchers suggest starting treatment if the last seizure was within the previous year [3]. We advocate for a more flexible initiation of antiepileptic treatment. Treatment of epilepsy always has to be considered on a multifactorial basis and includes the risk of recurrence based on seizure pathology (e.g., generalized versus focal epilepsy), seizure frequency, associated disease and available antiepileptic treatment, among others.

Epileptic seizures that are based on intracranial pathologies, such as parasitic disease, cerebrovascular accidents or trauma, and stop after the underlying cause, e.g. the associated oedema, has resolved, are called acute symptomatic epileptic seizures and have to be differentiated from epileptic seizures in the context of "chronic" epilepsy. In "chronic epilepsy" brain lesions may still be present, but they belong to the entity of neurological sequelae such as calcifications after parasitic diseases or chronic lesions in the context of cerebrovascular accidents or trauma, among others. These lesions most likely will not undergo further changes and therefore the "chronic" epilepsy type is treated symptomatically with antiepileptic drugs. In acute symptomatic epileptic seizures treatment of the primary cause is mandatory, if possible, but antiepileptic drugs are often added. After the acute phase withdrawal of antiepileptic treatment is desirable, but has to be decided on a case-to-case basis.

\subsection{Prevalence of epilepsy in sub-Saharan Africa}

In sub-Saharan Africa, epilepsy is among the most common neurological disorders. Its devastating impact on individuals suffering from it as well as on affected African communities was described as early as 1960 in Mahenge, southern Tanzania [4]. These early anecdotal reports were corroborated by a large-scale hospital-based study in Nigeria in the 1970s [5]. Since then, prevalence data on epilepsy have been collected in community-based studies throughout Africa with varying results depending on the study population and the methodologies used (mainly on active epilepsy), ranging from 5.2-74.4/1000 with a median of $15 / 1000$ inhabitants [6,7]. This is compared to high-income countries where the prevalence of active epilepsy is estimated to be about 4-8/1000 inhabitants [8]. Interestingly, hotspots of highly prevalent epilepsy have been reported in various African countries such as Benin, the Ivory Coast, Cameroon, Nigeria, Senegal and Tanzania [6,9]. Causes for these high prevalence rates have so far not been identified, but they are deemed to be partly genetic in nature, most likely with a consistent environmental factor that affects genetically predisposed individuals [6].

Our own data from a hospital-based study on neurological disorders in northern Tanzania show epileptic seizures to be the most prevalent neurological disorder [10,11]. Of the 740 patients with neurological symptoms/signs, $272(36.8 \%)$ had at least one epileptic seizure during their stay at the hospital or immediately before admission to the hospital. Febrile seizures $(82 / 272 ; 30.2 \%)$ accounted for the majority of epileptic seizures. This was followed by symptomatic epileptic seizures $(72 / 272 ; 26.5 \%)$, which were mainly due to cerebral 
infections, then epilepsy $(65 / 272 ; 23.9 \%)$ as defined by the International League Against Epilepsy [1]. Assumed symptomatic seizures without an obvious cause that did not meet the criteria of epilepsy occurred in $15.4 \%$ (42/272) and pseudoseizures were witnessed in $4.0 \%$ (11/272). The mortality rate of the patients with epileptic seizures was high with $18.8 \%$ (51/272). Peak mortality rates were found in people with symptomatic disease and those with assumed symptomatic epileptic seizures, at 38.9\% (28/72) and $31.0 \%(13 / 42)$, respectively. These results clearly show where the burden of neurological disorders in subSaharan Africa, in our case northern Tanzania, lies and have implications for the objective of delivering appropriate care for patients suffering from epileptic seizures [10].

The high prevalence rates of epileptic seizures/epilepsy found in the above hospital-based study were also confirmed in a community-based setting. Of the 7399 people who were visited in a community-based study in the same area the above hospital-based study was conducted 83 people were diagnosed with epilepsy and of those 64 had active epilepsy (last seizure within the last 5 years; [12]). The point prevalence of epilepsy within the study population of 7399 people was 11.2/1000 (95\% CI 8.9-13.9/1000) with an age-adjusted prevalence of $13.2 / 1000$. The prevalence of active epilepsy was 8.7/1000 (95\% CI 6.711.0/1000) with an age-adjusted rate of 9.1/1000. The majority of patients suffered from generalized epilepsies. Not surprisingly, three quarters of the people with epilepsy had never accessed any health facilities [12].

Our findings confirm high prevalence rates of epileptic seizures/epilepsy in the hospital and the community, which agrees with the results of previous epidemiological studies of epilepsy in sub-Saharan Africa [5,6,9,13-19]. Most studies conducted in parts of Africa and Latin America indicate higher prevalence rates of epilepsy than have been found in high-income countries, but these prevalence rates can vary within a single country, as shown in Benin, the Ivory Coast, Senegal and Tanzania [6,9,19]. In a recent large-scale study from Kenya, it was shown that the active prevalence was only 4.5/1000, and therefore in the range of prevalence rates of high-income countries, with a high heterogeneity of prevalence rates across different areas ranging from below 1.0/1000 to 12.9/1000 [3]. Active epilepsy was defined as at least one seizure during the last year (the usual definition is one seizure during the last five years; see 1.1.) which may account for the lower prevalence rate found.

\subsection{Classification of epileptic seizures/epilepsy in resource-poor settings}

Classifying epileptic seizures/epilepsy in resource-poor countries can be challenging, bearing in mind that the availability of diagnostic tools such as appropriate serological investigations, electroencephalography and neuroimaging can be scare or, especially in rural Africa, absent altogether. Whether the seizures reported in rural Africa are primarily generalized or focal in nature is still a matter of debate and depends upon the setting and methodology used (e.g. hospital-based versus community-based), the country of investigation, the questionnaires used (different sensitivities and specificities) and the diagnostic tools available [6]. While members of the International League Against Epilepsy have developed consensus papers on the best classification of epileptic seizures [20] and 
epilepsies [21,22] that are considered international standards, they mainly refer to highincome countries, which only include $20 \%$ of all people with epilepsy worldwide [23,24]. In contrast, appropriate classification systems for epileptic seizures/epilepsy in low-income countries seem to be virtually absent. Seizure semiology, the description of which can be incomplete due to language and sociocultural barriers, and important seizure related issues such as possible aetiologies and concomitant diseases (e.g. perinatal neurological sequelae) are relevant for the classification of epileptic seizures/epilepsy in these countries and should form parts of an adapted classification system. The growing relevance of global neurology together with the already substantial burden of epileptic seizures/epilepsy in sub-Saharan Africa calls for an expert-led committee to decide on an appropriate classification system for epileptic seizures/epilepsy for clinical use in low-resource countries.

We suggest a classification system that is based on clinical grounds alone, and mainly refers to the description of seizures provided by the patients and their relatives along with relevant information from past medical histories, birth and family histories and a thorough neurological examination. Electroencephalography and neuroimaging are not usually at hand in resource-poor settings and therefore are not included in the classification system. The classification system suggested is based on the classification of epileptic seizures and epilepsy as stipulated by the International League Against Epilepsy [1,20-22]. Based on our experience while working in northern Tanzania we identified four main categories of epileptic seizures/epilepsy that have different needs for further investigation, treatment and follow-up, showing variable prognoses ([25,26]; Figure 1).

Generalized types of seizure:

1. Generalized seizures within a specific age range: primary generalized seizures that start within a specific age group (mainly between 6 and 25 years). Seizures in this group can also be termed idiopathic generalized epilepsy.

Cause: none obvious

Prognosis: good

Investigations: keep to a minimum

2. Generalized seizures outside a specific age range: primary generalized seizures that start outside the specific age range of most of the idiopathic generalized epilepsies where no symptoms/signs on clinical examination suggest a secondary cause.

Cause: none obvious, seizures may be "cryptogenic".

Prognosis: variable

Investigations: further investigations necessary (electroencephalography, neuroimaging)

Partial types of seizure that clinically appear as generalized seizures:

3. Generalized seizures with diffuse brain damage: secondary generalized seizures that start in a generalized way, but diffuse brain damage with mental retardation is obvious. The large majority of patients are children.

Cause: mostly known (e.g. birth defect)

Prognosis: variable

Investigations: keep to a minimum 
4. Generalized seizures with focal signs: secondary generalized seizures with a focal start, clear unilateral seizures or focal neurological signs upon examination but without signs of diffuse brain damage.

Cause: may become obvious upon further investigation

Prognosis: depends on the underlying cause

Investigations: further investigations necessary (electroencephalography, neuroimaging)

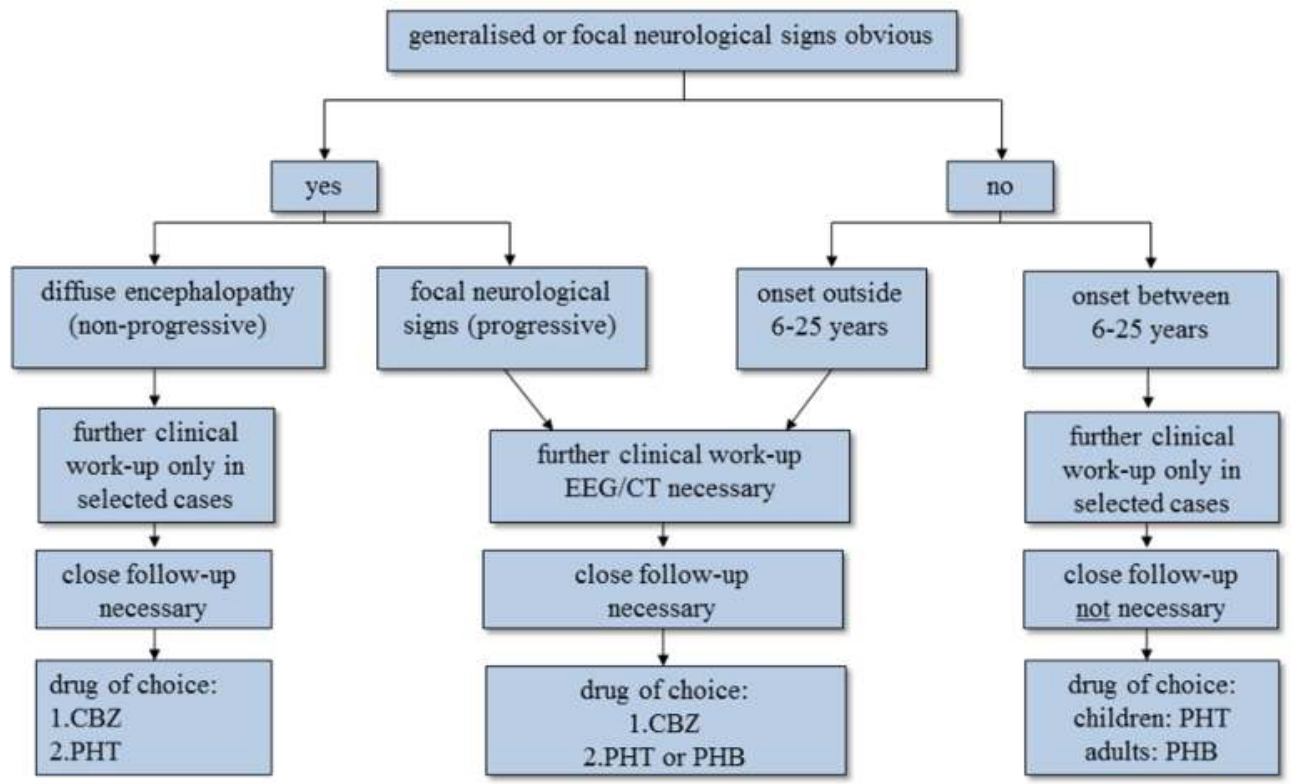

Figure 1. Algorithm on how to classify people with epilepsy in resource-poor countries regarding diagnostic and therapeutic implications. Primary generalised seizures are split according to the age of onset (see text); these two groups have a different diagnostic and therapeutic approach. Patients with primary generalised seizures that start outside 6-25 years are more likely to have cerebral lesions than patients whose epilepsies start within 6-25 years where idiopathic epilepsy prevails, and therefore need further investigation. In people with epilepsy and diffuse brain damage, diagnostic tests are rarely needed as the extent of the cerebral sequelae is known and the condition is not progressive. In contrast, in people with epilepsy who show focal signs without diffuse brain damage, further diagnostic steps are essential in order to identify the underlying, potentially treatable cause. In all four groups, treatment depends mainly on the age of the patient, seizure activity, seizure frequency, the presence of mental handicap and the presence of focal neurological signs, bearing in mind that the choice of antiepileptic medication is limited. $\mathrm{CBZ}=$ carbamazepine, $\mathrm{PHT}=$ phenytoin, $\mathrm{PHB}=$ phenobarbitone.

We opted for a simply structured, easy-to-understand classification system that mainly consists of the four groups of epileptic seizures/epilepsy described above based on seizure description, clinical information and a physical examination (Figure 1). Our classification shares many similarities with the International League Against Epilepsy classifications [1, 20-22], especially the International Classification of Epileptic Seizures [20], but it has been 
tailored to fit local circumstances. This was deemed important in order to gain information on possible causes, necessary investigations within a resource-poor setting, best antiepileptic treatments and prognoses of seizure disorders (Figure 1).

The "generalized types of seizure" (groups 1 and 2; Figure 1) were divided according to age at onset. They presented as classic primary generalized seizures without any suggestion of focal neurological signs or focal seizure onset. The subdivision of primary generalized seizures into those that start within a specific age range (6-25 years;[27]) and those that start outside of this age range was deemed important as the approach used for each is different (Figure 1). Idiopathic epilepsy types include distinct seizure syndromes with distinct ages of onset, although mainly within the postulated age group of 6-25 years [27-29]. Primary generalized seizures outside of this age range, either below about 6 years or above about 25 years, can still be idiopathic in nature, although seizures caused by brain lesions, especially in a resource-poor setting, may prevail. Our hospital-based study showed that symptomatic seizures are frequent. When looking at the exact age distribution, $70.8 \%$ (51/72) of the patients with symptomatic seizures were aged either below 6 years or above 25 years when presenting with symptomatic seizures [10]. Therefore, for people with epilepsy presenting with primary generalized seizures that fall into these age groups, further investigations with electroencephalography and neuroimaging seem to be important (Figure 1).

The "partial types of seizure with the clinical appearance of generalized seizures" (groups 3 and 4; Figure 1) were divided according to the extent of brain damage associated with the seizures. Mental retardation and intellectual decline due to serious brain disorders in children of resource-poor countries are much more frequent compared to resource-rich countries [30,31]. These are often associated with epileptic seizures that are difficult to treat and have an unfavourable prognosis [32]. Thus, this group of people with epilepsy deserves special attention, and therefore has been summarized as a separate group (group 3). In children with more widespread brain damage, antiepileptic drugs with sedative effects such as phenobarbitone could further hamper intellectual development. Often, additional diagnostic tests do not add to the management of these young patients as the cause of cerebral sequelae is known and the condition is not progressive (Figure 1). "Overdiagnosing" patients in this context can cause unnecessary financial burden to the families.

Epilepsy in resource-poor countries is often associated with brain lesions of various origins, with infection and trauma being the most important causes in this setting $[2,33]$. These patients can show focal neurological signs and/or present with clinically obvious secondary generalized seizures, but, in contrast to group 3, they do not show signs of more widespread brain damage. Often, a patient is previously healthy before a special event precedes the onset of seizures, although this is not mandatory. Further diagnostic procedures in these patients are important in order to identify the underlying, potentially treatable cause of the epilepsy (Figure 1).

In summary, we have identified four major groups of epileptic seizures on clinical grounds that are relevant to the diagnosis of epilepsy in sub-Saharan Africa. The suggested investigations within a resource-poor setting, treatment and prognosis differ between the 
groups, and a classification of affected patients within the most appropriate group could help guide the clinician towards the appropriate management of people with epilepsy within a rural African setting.

\subsection{Treatment gap of epilepsy in sub-Saharan Africa}

In many African countries, epileptic seizures/epilepsy represent a tremendous socio-economic burden, partly due to the chronicity of the disease, and therefore not only have repercussions on individuals but also on their families and the community they live in. The figures released by the WHO are convincing: 50 million people worldwide suffer from epilepsy; $80 \%$ of them live in resource-poor countries [23] and of these up to $90 \%$ are untreated or treated insufficiently [34]. Newer figures indicate that 63 million people live with epilepsy in low- and middle-income countries [35]. This $90 \%$ treatment gap was corroborated by studies from northern and southern Tanzania showing that $76 \%$ and $95 \%$ of people with epilepsy, respectively, had not been treated [12,19]. Dramatic global disparities in this treatment gap were identified by a systematic review which showed that $75 \%$ and fewer than $10 \%$ of PWE from low-income and high-income countries, respectively, were untreated or insufficiently treated for their epilepsy [36]. A recent study from Kenya demonstrated an epilepsy treatment gap of $62 \%$ using serum antiepileptic drug levels as a measure of compliance and found that self-reporting of compliance to antiepileptic medication was very unreliable when compared to the serum antiepileptic drug levels $[37,38]$.

Although access to modern medicine is limited for people with epilepsy who live in subSaharan Africa, traditional medicines are widely used as they represent the only treatments that are accessible to most of the affected population. The lack of awareness of local and international policy makers, poor infrastructure, long travel distances, the insufficient or only intermittent availability of antiepileptic medications, the lack of education among people with epilepsy, their families and the communities, the predominance of traditional belief systems and the scarcity of trained medical personnel may be responsible for this large treatment gap $[39,40]$. Another important but often neglected cause of this treatment gap is social stigma. In many countries of sub-Saharan Africa, epilepsy has mystical connotations, which is another reason why the majority of people with epilepsy resort to traditional medicines before even considering modern medicine. In many societies, epilepsy is viewed as punishment for sins or breaking taboos, a curse, bewitchment or demoniac possession, as well as a contagious disease, resulting in the rejection and discrimination of affected individuals [41]. A recent study from Zambia showed that people with epilepsy are disadvantaged regarding social and economic matters compared to people with other chronic diseases without an attached stigma, such as asthma, diabetes mellitus, hypertension and rheumatic heart disease [42]. The aforementioned aspects all contribute to the fact that the majority of people with epilepsy go untreated. This treatment gap is the main cause of individual suffering and the socio-economic burden of the disease, necessitating improvements in therapeutic strategies [6,43,44]. A pre-requisite for successful treatment also includes a good knowledge of the possible aetiologies of seizure disorders as treatment can largely depend on underlying pathologies. 


\subsection{Causes of epileptic seizures/epilepsy in sub-Saharan Africa}

Causes of epileptic seizures/epilepsy are highly variable across different regions of subSaharan Africa and depend on geographical, climatic, political, social and hygienic conditions. However, the main and most important causes of epilepsy seem to be very similar throughout sub-Saharan Africa and have been studied in great detail, both in hospital and community settings, showing that a positive family history (genetic predisposition), a past history of febrile convulsions, perinatal neurological disorders, head injuries, cerebrovascular accidents and infections of the central nervous system account for most cases of epilepsy [6]. Also included are a variety of protozoon (the most important being cerebral malaria) and helminthic infections, of which Taenia solium (its larval stage causing cysticercosis) has attracted considerable attention in sub-Saharan Africa over the past few years. Therefore, epileptic seizures/epilepsy in the context of NCC will be described in more detail in the following paragraphs in order to provide adequate information on clinical characteristics, diagnosis and treatment in the context of sub-Saharan Africa.

\section{Prevalence of neurocysticercosis in sub-Saharan Africa}

NCC represents the most common helminthic infection of the central nervous system [45] and is endemic in most countries of Latin America, Asia and sub-Saharan Africa. NCC is not only one of the major causes of acquired epileptic seizures/epilepsy in low-resource countries, but it is also of increasing concern in so far non-endemic countries, such as Europe and the United States, due to globalization and the migration of infected people [46-50].

Community-based estimation of the prevalence of NCC is difficult as neuroimaging would have to be applied to a large population putting seemingly healthy people at risk of radiation and therefore has been performed rarely so far [51]. In contrast, the prevalence of human Taenia solium cysticercosis in communities has been assessed as this requires blood analysis only. In cysticercosis endemic areas of the Democratic Republic of Congo, Burkina Faso and Zambia the prevalence of Taenia solium cysticercosis as measured with an antigenELISA was $22 \%, 10 \%$ and $5.8 \%$, respectively [52-54]. Indirect approaches are used to get an impression about the prevalence of people with NCC in a certain population and often people suffering from epileptic seizures or epilepsy are included into these studies. The prevalence of epilepsy has shown to be high in a Taenia solium cysticercosis endemic area from Burkina Faso which found an epilepsy lifetime prevalence of 4.5\% [55]. A recent metaanalysis on the prevalence of NCC in people with epilepsy, including 12 studies mainly from Latin America, India and sub-Saharan Africa, found that NCC was the cause of epilepsy in almost $30 \%$ of people with epilepsy [56].

If extrapolating the above results to the entire population of sub-Saharan Africa (850 million people; [57]) and assuming a prevalence of epilepsy of 4-13/1000 [3,12], approximately 3.4 to 11.05 million people would suffer from epilepsy. Thirty per cent of it is due to NCC yielding 1.02-3.32 million people with epilepsy due to NCC in sub-Saharan Africa. Epilepsy makes up for approximately $80 \%$ of the symptoms in NCC [58] and therefore 1.28-4.15 million people would suffer from symptomatic NCC including all neurological signs/symptoms (see 
2.4.). We also know that symptomatic NCC is only the tip of the iceberg and that the majority of people with NCC are asymptomatic. We assume conservatively $50 \%$ of all NCC cases to be asymptomatic [59]. Therefore the total of all people suffering from NCC in subSaharan Africa would be somewhere between 2.56-8.30 million. These figures would however come down if only areas confirmed with endemic Taenia solium cysticercosis would be considered. Currently a number of 631776908 people has been assumed to live in the Taenia solium cysticercosis endemic areas of sub-Saharan Africa (endemic countries: [60]; populations in these endemic countries: [61]) yielding an NCC-based epilepsy population of 0.76-2.46 million and a population suffering from symptomatic NCC of 0.95-3.08 million. The same amount of people would suffer from asymptomatic NCC, if assuming that $50 \%$ of all cases are asymptomatic.

Latent NCC cases when harbouring Taenia solium cysticerci can become symptomatic at any time due to the natural course of disease or in the context of treatment received for intestinal parasites [62]. These people are also at risk of developing symptomatic disease through mass drug administration for soil-transmitted helminths and schistosomiasis, among others [63-66]. Praziquantel and albendazole, two antihelminthic drugs (see 2.6.1.), are at the heart of mass drug administration and may be able to convert latent NCC to symptomatic NCC by destroying the parasite and potentially provoking brain oedema [65,66]. Anecdotal reports of sudden onset of serious neurological signs and/or death after mass drug administration have been noted, but to date no large-scale studies on the topic of the side effects after mass drug administration in carriers of latent cysticerci have been performed. Such studies are desperately needed to evaluate the risk of symptomatic NCC with potentially ensuing death in many hundreds of thousands of people in sub-Saharan Africa. For more details on the calculation of how many people in sub-Saharan Africa would potentially be at risk of developing neurological side effects after mass drug administration of praziquantel and albendazole refer to Winkler [67].

NCC not only imposes a huge socioeconomic burden onto the health systems of affected African nations (see 2.3.), but also indicates that people who potentially could be cured from their epilepsy by antihelminthic medication are practically left untreated. Data on subSaharan prevalence rates of NCC in people with epileptic seizures/epilepsy are mainly based on serological results and only exist from a few countries with results of over $40 \%$ (Cameroon) depending on the serological tests used [68-70]. A recent meta-analysis that only included African studies showed a significant association between epilepsy and cysticercosis with an odds ratio of 3.4 [71]. More details on the prevalence of NCC (serology and imaging) are available from South African studies [68], where one study found $50.6 \%$ of newly diagnosed people with epilepsy showing lesions of NCC on neuroimaging [72]. The only neuroimaging-based study in sub-Saharan Africa outside South Africa was performed from our own group. Definite NCC lesions on computed tomography (CT) were demonstrated in $2.4 \%(5 / 212)$ of people with epilepsy, lesions highly suggestive of NCC were present in $11.3 \%(24 / 212)$ and lesions compatible with NCC were found in $4.2 \%(9 / 212)$. The NCC lesions were significantly more frequent in people with epilepsy compared to the controls [73]. 
Although it was clearly demonstrated that NCC in people with epilepsy from sub-Saharan Africa is prevalent, there is still some controversy regarding the manifestation of NCC in different age groups. In a recently conducted study, there was a trend of people with epilepsy and NCC being older and having their first seizure later compared to people with epilepsy without NCC [74]. Other studies also report that NCC is the cause of late-onset epilepsy [75-78]. A possible reason might be that older people with epilepsy are more susceptible to the infection. However, especially the calcified stage of NCC was found to be more common in younger people with epilepsy, whereas cysts were found to be more common in older people with epilepsy $[73,74]$. This may be explained by a different immunoresponse to the infection with age. The age of first manifestation of NCC seems however difficult to obtain, especially in sub-Saharan Africa, as children are often excluded from neuroimaging studies for obvious ethical reasons, although several reports have demonstrated the presence of NCC among children [79-83].

\subsection{Neurocysticercosis in people with HIV/AIDS}

Most NCC endemic areas are also endemic for HIV/AIDS and interaction of the two diseases, as known for HIV/AIDS and malaria and HIV/AIDS and tuberculosis, would seem plausible. Indeed, acceleration of the clinical course of HIV/AIDS in patients co-infected with Taenia solium cysticerci has been suggested based on the manipulation of the immune system by the parasite [84,85]. In South Africa, NCC has been described as one of the most important focal brain lesion in people with HIV/AIDS with neurological signs depending on the location of the lesion. Interestingly intraventricular NCC seems to be especially common in patients with HIV/AIDS from South Africa presenting with epileptic seizures and signs of increased intracranial pressure, among others. Treatment with ventriculo-peritoneal shunts carries a bleak prognosis, whereas antihelminthic medication together with steroids shows a better outcome in these patients. These reports from South Africa are fairly worrying and repeated regular treatment with short courses of praziquantel together with steroids have been advocated for HIV/AIDS patients from highly endemic areas to reduce the rate of re-infection which may accelerate the course of disease, if left untreated [84]. However, to date no systematic studies on co-infection with Taenia solium cysticerci and HIV have been conducted in sub-Saharan Africa. Observations from South Africa indicate that co-infection is high $[84,85]$. Conversely, studies from India and Mexico have shown that seroprevalence of Taenia solium cysticercosis in patients with HIV/AIDS is lower than in the non-HIV/AIDS population, which may point to an impaired immunoreaction with unreliable detection of Taenia solium cysticercosis antibodies [86,87]. The fact of unreliable Taenia solium cysticercosis serodiagnosis could present a substantial problem in the HIV/AIDS population with focal neurological signs in whom tuberculous meningitis/tuberculoma and toxoplasmosis, two diseases with different therapeutic approaches, represent the most important differential diagnoses.

\subsection{Monetary burden of neurocysticercosis in sub-Saharan Africa}

A comprehensive estimate of the monetary burden of cysticercosis in the Taenia solium cysticercosis hyperendemic Eastern Cape Province of South Africa indicated the monetary 
burden per capita to be between US\$ 2.6 and US\$ 4.8, which is substantial when compared to annual health expenditures of US\$ 41.3 per capita for people living in poor dwellings in that province. The overall monetary burden was calculated to vary from US\$ 18.6 million to US\$ 34.2 million depending on the method used to estimate productivity losses. The epilepsy prevalence of the Eastern Cape Province, the proportion of people with epilepsy seeking medical care and the proportion of epilepsy cases attributable to NCC as well as the proportion of work time lost due to NCC were found to have the most influence on the estimated monetary burden [88]. The total societal costs due to Taenia solium cysticercosis in the main pig breeding region of West Cameroon (West, Southwest and Northwest Provinces) was also recently estimated [89]. Based on an epilepsy prevalence of $3.6 \%$, the number of people with NCC-associated epilepsy was estimated at 50326 , representing $1.0 \%$ of the local population, whereas the number of pigs diagnosed with cysticercosis was estimated at 15961 (based on lingual examination results), which corresponds to $5.6 \%$ of the local pig population. The total annual costs due to Taenia solium cysticercosis in West Cameroon were estimated at $€ 10.3$ million, of which $4.7 \%$ were due to losses in pig production and $95.3 \%$ to direct and indirect losses caused by human Taenia solium cysticercosis. The monetary burden per case of human NCC amounted to $€ 194$ and the average number of Disability-Adjusted Life Years (DALYs) lost was 9.0 per thousand persons per year which was higher than estimates for some other neglected tropical diseases [89].

\subsection{Staging, pathology and clinical characteristics of neurocysticercosis}

In humans, after the ingestion of Taenia solium eggs, oncospheres hatch and penetrate the gut wall. They are transported via the bloodstream and cysticerci form within a few weeks/months, mainly in subcutaneous tissue (painless, palpable, cystic lesions), skeletal muscle (lesion may not be palpable), the eye and the central nervous system, particularly in the brain but also in the spinal cord ([90]; Figure 2). Differences in phenotype of cysticercosis between various regions of the world have been described, indicating that the subcutaneous form of cysticercosis is most frequent in Asia, least prevalent in Latin America and that reports of its occurrence are conflicting in sub-Saharan Africa [67]. Especially cysticercosis of the eye and central nervous system are of clinical importance, where cysticerci can cause inflammation and/or space-occupying lesions with a mass effect and/or obstruction with resulting hydrocephalus.

In the brain, immature cysticerci appear within 1-4 weeks after the ingestion of eggs (stage 1). After approximately 1 month, this phase is followed by the maturation of cysticerci, which happens with surprisingly little or no inflammation (stage 2). This stage can last for more than 10 years and cysticerci survive by disarming host defences. Neurological symptoms and/or signs are not usually reported. Stage 3 (2-10 years or more after cysticerci maturation) is characterized by an intense host immunoresponse leading to the degeneration of cysticerci (granuloma), which may now cause neurological symptoms and/or signs [91]. The reasons for cysticerci to eventually be recognized by the host and thereby to go from stage 2 to stage 3 have not been understood so far. Antihelminthic treatment seems to accelerate this transition, as often the administration of antihelminthic 
medication causes perifocal oedema surrounding the parasite [62]. In stage 4, the inflammatory response has resolved, either without scarring or leaving behind residual calcifications ([91]; Figure 2).

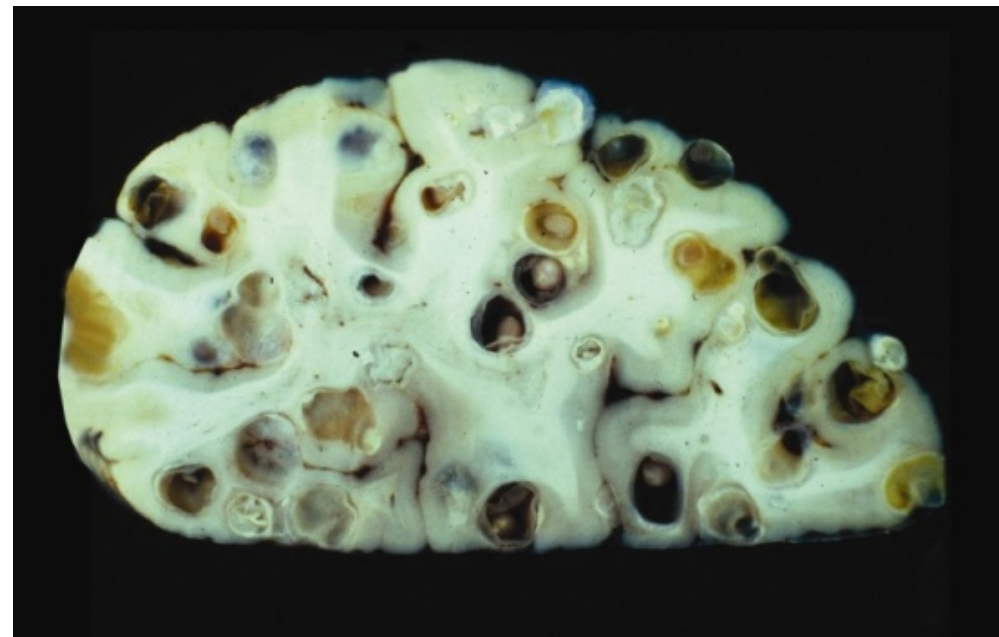

Courtesy of Prof. Theodore Nash who has also given permission for reproduction, Laboratory of Parasitic Diseases, National Institutes of Allergy and Infectious Diseases, National Institutes of Health, Bethesda, Maryland, USA.

Figure 2. Cross-section of a human brain showing various stages of neurocysticercosis, including cysts showing the scolex (stage 2), granulomas with surrounding inflammation (stage 3 ) and calcifications (stage 4). For more details refer to section 2.4. in the main body of the text.

NCC can cause a variety of symptoms and signs depending on the number, size, stage and location of the pathological changes as well as the host's immunoresponse and the parasite's genotype, or it can also be clinically asymptomatic. Post-mortem studies have shown that in up to $50 \%$ of people with NCC the cerebral lesions were asymptomatic [59]. There may be single or multiple cysticerci in the brain (intraparenchymal NCC, approximately $80 \%$; Figure 2) and, in extreme cases, encephalitis (Figure 2) may ensue. Single enhancing (intraparenchymal) lesions (SEL) represent a separate entity that has been described mainly in patients from the Indian subcontinent. Differential diagnosis is difficult and may encompass tuberculoma, toxoplasmosis, brain abscess and tumours, among others. A lesion $<2 \mathrm{~cm}$ in diameter without gross perifocal oedema and subsequent growth is likely to represent a degenerating Taenia solium cysticercus. Patients mainly present with partial onset seizure with or without generalisation and have a high risk of seizure recurrence. Contrary to India, multiple lesions mainly of the intraparenchymal type seem to prevail in people with NCC from Latin America, sub-Saharan Africa and other Asian countries although scientific publications on NCC-related neuroimaging from sub-Saharan Africa and Asian countries other than India are rare $[67,92,93]$.

Cysticerci can also occur in the ventricular system and/or the subarachnoid space (extraparenchymal NCC, approximately 20\%), which is often associated with 
intraparenchymal NCC. Ventricular disease may cause ependymitis and/or increased intracranial pressure. Arachnoiditis, especially in the basal cisterns, which can lead to communicating hydrocephalus, vasculitis and/or compression of cerebral vessels, can result from subarachnoid disease. Intramedullary cysticerci can be found in the spinal cord, causing focal neurological symptoms/signs, and extramedullary cysticerci can cause radicular symptoms and/or signs [94].

If cerebral cysticerci or calcifications are intraparenchymal, epileptic seizures and/or epilepsy may ensue [95,96]. During stage 3 of cyst degeneration new-onset acute symptomatic epileptic seizures can occur that usually resolve after the inflammation has died down, which is very characteristic of this phase. In the case of remaining calcifications, recurrent epileptic seizures, i.e. epilepsy, can develop, although fortunately most patients remain asymptomatic ([91,97]; see 1.1.). The majority of cysticerci calcify, but cysticerci may also become invisible on CT and magnetic resonance imaging (MRI). Although the parasite is assumed dead, intermittent flares of oedema around calcifications have been described and they seem to be associated with increased seizure activity. The mechanisms of oedema occurrence however is not fully understood, but increased antigen accessibility with subsequent enhanced immunoresponse have been suggested. Another cause for the development of epilepsy after cyst resolution is the development of perilesional gliosis around calcifications secondary to prior inflammation [97].

A systematic review on the clinical manifestations in people with NCC showed that the majority of symptomatic adult cases (78.9\%) had epileptic seizures [58]. This may be the only presentation, especially in people with single enhancing granulomatous lesions that bears a good prognosis compared to infection with multiple cysticerci [92]. Epileptic seizures were followed by headaches in $27.7 \%$ of people [58]. Headache in people with NCC can be acute or chronic, and presents as tension-type or migraine-like episodes $[98,99]$. Headache can also indicate raised intracranial pressure [90]. Furthermore, adults with NCC also present with focal neurological signs (11.8\%), signs of intracranial hypertension $(16.3 \%)$, meningitic symptoms (5.6\%), gait abnormalities (5.6\%) and altered mental state/psychiatric symptoms (28.1\%), among others [58]. Forlenza et al. [100] examined 38 cases with NCC and found cognitive decline in $87.5 \%$ and psychiatric illness in $65.8 \%$ of them, with depression and psychosis being the most frequent psychiatric disorders. These findings were corroborated by a study from Brazil which showed that cognitive impairment was ubiquitous in 40 patients with NCC and that dementia was obvious in $12.5 \%$ [101]. A recent interesting and well conducted study, although small in sample size, showed that people with new-onset epileptic seizures and NCC performed worse on cognitive tests including scores for attention, processing speed, learning and memory compared to controls with and without epilepsy (people with epilepsy unrelated to NCC and healthy neighbourhood controls). However, the difference was only significant for the attention score (people with epilepsy and NCC compared to epilepsy controls). Over time (6 month-follow up) people with NCC-based epilepsy, who were all treated with albendazole, had significant improvement in psychomotor speed and working memory, but there were no significant changes in any of the cognitive test scores above, although a general trend for better 
performance after treatment was visible. Both epilepsy groups were controlled for seizure frequency and antiepileptic medication was kept constant during the study period [102].

In children with NCC from a series of studies conducted in Latin America, mainly single colloidal parenchymal cysts were seen, but heavy infection was also described. Calcifications were seen less often and the development of hydrocephalus, and basal subarachnoid disease seemed to be rare $[83,103,104]$. The most frequent clinical presentation in children is epileptic seizures followed by headaches and signs of elevated intracranial pressures. The only major difference compared to adults was that children portrayed relatively little psychiatric symptoms [58].

\subsection{Diagnosis of neurocysticercosis including information on sub-Saharan Africa}

A suspected diagnosis of NCC (e.g. epileptic seizures in a patient from an area endemic for Taenia solium cysticercosis) should be confirmed with a combination of neuroimaging and serology, if possible. On neuroimaging cysts, granulomas and/or calcifications will support the clinically based suspicion of NCC. However, these lesions may also be caused by other pathogens and pathological processes and therefore combination with Taenia solium cysticercosis serology is highly desirable. Both, neuroimaging and Taenia solium cysticercosis serology are often not available in resource-poor settings, but routine cerebrospinal fluid analysis may point the direction and can be obtained from patients without major impairment of consciousness. Cerebrospinal fluid analysis in NCC very often is unremarkable, but it may also show signs of parasitic disease, especially in multicystic disease and intraventricular/subarachnoid forms of NCC, including slightly elevated cell count (usually not exceeding 100 cells $/ \mu \mathrm{l}$, demonstrating mononuclear pleocytosis and eosinophilia) and increased protein levels in the range of 50 to $300 \mathrm{mg} / \mathrm{dl}$. Glucose levels are usually normal [105].

Today a wide array of serological tests for Taenia solium cysticercosis exist such as the antigen/antibody enzyme-linked immunosorbent assay (ELISA) and immunoblots which can be performed in serum and/or cerebrospinal fluid of suspected cases [90,106-111]. However, a positive test only indicates cysticercosis but not necessarily NCC, and the sensitivity and specificity for current infection with Taenia solium cysticercus and prior exposure to the parasite can vary considerably according to the test used [106, 108, 112]. In addition, polymerase chain reaction (PCR) methods for the diagnosis of Taenia solium cysticercosis are under development, but so far are not part of routine diagnosis due to varying levels of sensitivities and specificities [113,114]. Also, these techniques, with highcost equipment and need for regular maintenance may not be suitable for countries of subSaharan Africa.

When it comes to the availability of Taenia solium cysticercosis serological tests in subSaharan Africa the information is scarce and relies on personal communication. I therefore suggest that one of the tasks of the next Cysticercosis Working Group in Eastern and Southern Africa (CWGESA) meeting should be the establishment of an accurate list of Taenia 
solium cysticercosis immunodiagnostic tests available in countries of sub-Saharan Africa. The information I have got so far, even after communicating with various stakeholders, is not much different form the information published in Winkler et al. [110] and therefore would need updating by talking to reference people of the individual countries. In summary, in Mozambique and South Africa Taenia solium cysticercosis antibody-ELISA has been available for some years (personal communication with Dr Lee Willingham, WHO, Geneva, Switzerland). My own cysticercosis project in collaboration with the Department of Infectious Disease and Tropical Medicine of the University of Munich and funded by the German Research Foundation is currently transferring capacity for Taenia solium cysticercosis antibody-ELISA to the CWGESA Regional Reference Centre for Immunodiagnosis of Taenia solium Infections at the University of Zambia, to Gulu University of Uganda and to Muhimbili University of Health and Allied Sciences of Tanzania. There are also plans to transfer the new T24 recombinant-based antibody-ELISA test developed by the U.S. Centers for Disease Control and Prevention to Zambia, Mozambique and Madagascar (personal communication with Dr Lee Willingham, WHO, Geneva, Switzerland) and according to the latest information training of personnel has started (personal communication with Dr Patricia Wilkins, U.S. Centers for Disease Control and Prevention, Atlanta, USA). Diagnostic possibilities for Taenia solium cysticercosis in terms of immunoblot currently do not exist in countries of sub-Saharan Africa. A Taenia solium cysticercosis antigen-ELISA has been performed over the last years in Zambia at the CWGESA Regional Reference Centre for Immunodiagnosis of Taenia solium Infections at the University of Zambia. Member countries of the CWGESA send samples for antigen-ELISA testing to this reference laboratory. Recently, antigen-ELISA facilities have also been established in Mozambique, Madagascar, South Africa, Burkina Faso and Cameroon (personal communication with Dr Lee Willingham, WHO, Geneva, Switzerland). Confirmation whether these tests are still functional has not been obtained from the individual countries, but could be included into the working schedule of the next CWGESA meeting.

Although positive serological and/or DNA-based tests may give the first indication, the gold standard of NCC diagnosis is neuroimaging, including CT and/or MRI, both of which are generally not available in sub-Saharan Africa. In neuroimaging, only a lesion showing the scolex (= head of the parasite) is classified as a definite NCC lesion and considered pathognomonic $[90,106,107,109]$. Active NCC is defined as the presence of any cystic lesions (with or without scolex) or lesions with ring enhancement. In contrast, parenchymal calcifications are classified as inactive [95,97].

Cysts are best visualized on MRI, whereas CT is the imaging of choice for calcifications. Cyst fluid shows the same signal than cerebrospinal fluid and is hypointense (dark signal) on T1weighted images as well as fluid attenuated inversion recovery (FLAIR) sequences and hyperintense (bright) on T2-weighted images. In the vesicular stage of NCC, there is no surrounding oedema. Cysts are usually $1-2 \mathrm{~cm}$ in diameter and the scoleces inside the cysts 1-2 $\mathrm{mm}$. The latter is isointense relative to brain parenchyma (Figure 3a). During the degenerative process with thickening of the cyst wall, increased protein content of the cyst fluid and surrounding inflammatory signs, the signal intensity of the cyst fluid is higher 
than that of cerebrospinal fluid on T1-weighted images, but still hypointense compared to parenchyma, and hyperintense on T2-weighted images (colloid vesicular stage), whereas the cyst wall is hyperintense on T1- and hypointense on T2-weighted sequences. As the degeneration goes on with proliferation and retraction of the cyst wall and reabsorption of the fluid (granular nodular stage) the granuloma becomes isointense and eventually hyperintense on T1- and hypointense on T2-weighted images. Ring-enhancement or total enhancement of the degenerative cysticerci after application of contrast indicates inflammation and subsequent disruption of the blood-brain barrier with leakage of plasma into cerebral tissue and is best visualized on T1-weighted images (Figure 3b). Perifocal oedema is best seen on FLAIR sequences (bright signal) and T2-weighted images (less bright signal). Calcifications (nodular calcified stage) often go unnoticed on MRI or may appear as small iso- or hypointense lesions on T1- and T2-weighted images [115]. Subarachnoid NCC shows multiple cystic masses in the basal cisterns or Sylvian fissure, among other locations. The masses may be lobulated and compress adjacent structures. Signal intensity usually compares with that of cerebrospinal fluid on all magnetic resonance sequences and is best seen as dark signal in T1-weighted and FLAIR images (Figure 3c). Ventricular NCC shows best on T1-weighted sequences, because on T2-weighted images the high signal intensity of the cyst fluid is indistinguishable from that of the cerebrospinal fluid (refer to chapter on extraparenchymal NCC) [115]. On CT scan cysts are hypodense (Figure 4a) and granuloma may be isodense to the parenchyma and only be seen after administration of contrast (Figure 4b). Calcifications are hyperdense (Figure 4c). Extraparenchymal NCC can easily be missed on CT, especially the ventricular form.

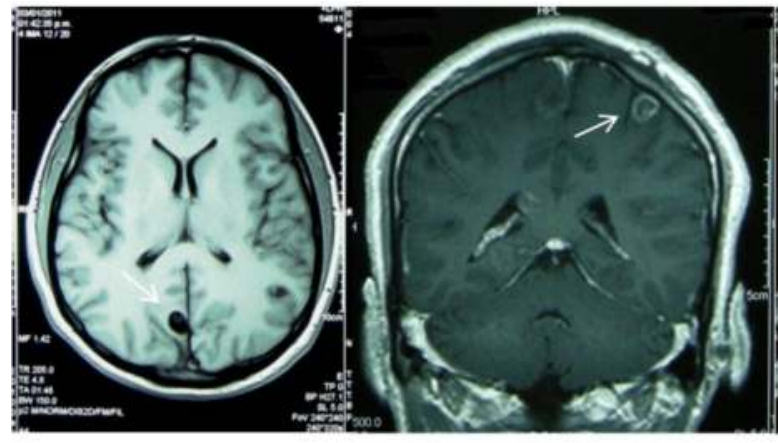

a) b)

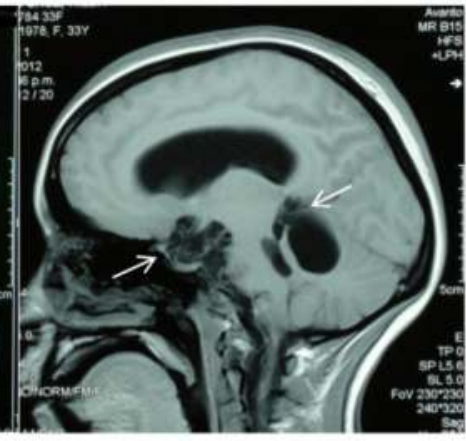

c)

All pictures are courtesy of Prof. Hector H. Garcia, Department of Microbiology, School of Sciences, and Director Center for Global Health - Tumbes, Universidad Peruana Cayetano Heredia, Lima, Peru.

Figure 3. a-c): magnetic resonance images of neurocysticercosis lesions; 3a) axial T1-weighted image showing a pathognomonic cyst with scolex (approximate diameter of $1 \mathrm{~cm}$ ) in the right occipital lobe; $3 b)$ coronal T1-weighted contrast enhanced image, showing a cystic lesion with an enhancing rim in the left parietal lobe; 3c) sagittal T1-weighted image showing extraparenchymal subarachnoid cysticercosis with multiple, lobulated cystic lesions predominantly in the subarachnoid space (prepontine, suprasellar cistern and cisterna ambiens) as well as probable intraventricular lesions with potential dilation of the $4^{\text {th }}$ ventricle. 


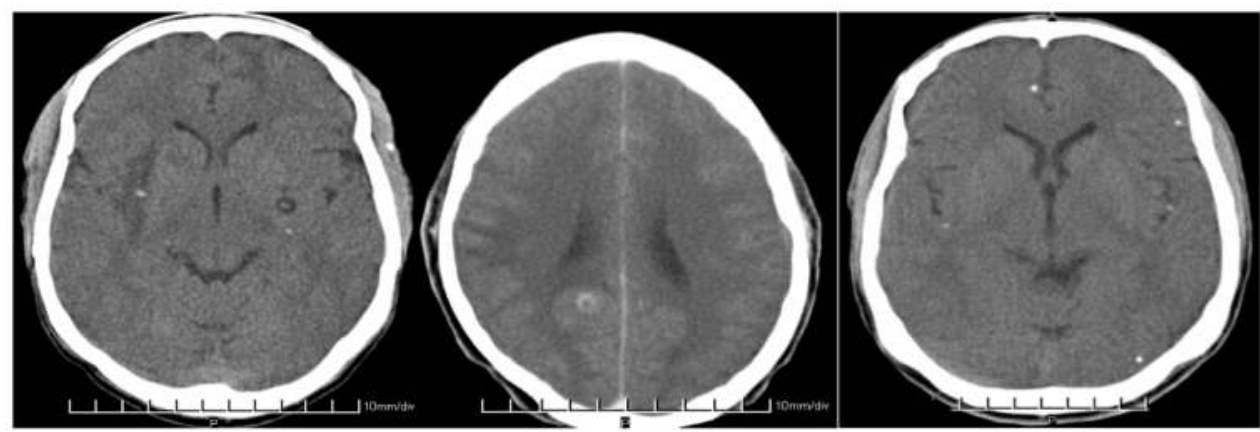

a)

b)

c)

Permission for reproduction has been obtained from SpringerWienNewYork. The pictures were originally published in Winkler AS, Willingham L 3rd, Sikasunge CS, Schmutzhard E. Epilepsy and neurocysticercosis in sub-Saharan Africa. Middle European Journal of Medicine 2009; 121 (suppl 3): 3-12.

Figure 4. a-c) axial computed tomography images of various stages of neurocysticercosis lesions; 4a) pathognomonic subcortical cyst left showing the scolex with a close-by calcification; calcified subcortical cyst right with perifocal/perilesional oedema; calcification in the left temporal muscle; $4 \mathrm{~b}$ ) "ring enhancing lesion" due to a degenerating subcortical cyst in the right occipital lobe; 4c) several scattered intraparenchymal calcifications most likely in the context of neurocysticercosis.

In a resource-rich setting the combination of MRI and CT makes a lot of sense to neither miss cystic lesions or granulomas nor calcifications. Combination of neuroimaging and immunodiagnostic test is strongly advised and their results together with clinical, pathological and epidemiological criteria as well as response to treatment with antihelminthic drugs are summarized in the diagnostic criteria for NCC suggested by Del Brutto et al. [107,109,116]. If neither immunodiagnostic tools nor neuroimaging are available, extirpation of subcutaneous nodules and a thorough ophthalmological examination may support the suspected diagnosis $[107,109,116]$. Due to an emphasis on neuroimaging and serological tests, the Del Brutto criteria seem to be rather impractical for its use in resource-poor settings and may need adjustment to suit local circumstances.

\subsection{Treatment of neurocysticercosis with a focus on sub-Saharan Africa}

In the treatment of NCC, symptomatic (steroids, antiepileptic medication, analgesics) and potentially curative treatment (antihelminthic medications) has to be differentiated. Indication and contraindication for antihelminthic treatment as outlined below must be observed. Neuroimaging is mandatory to start treatment with antihelminthic drugs and therefore antihelminthic treatment is not indicated in most patients from sub-Saharan Africa (except South Africa), where neuroimaging is absent. If there is any doubt as to the appropriateness of antihelminthic treatment, symptomatic treatment should be favoured. In addition, the treatment approach in acutely symptomatic and life-threatening disease is different form the more chronically symptomatic condition (see 2.5.1.). 


\subsubsection{Antihelminthic and/or anti-oedematous treatment}

Currently, there are no standard treatment guidelines for NCC; therefore treatment has to be tailored to the individual case. Only active disease needs treatment with antihelminthic drugs and/or steroids. Dosages and the duration of treatment can be highly variable and mainly depend on the number, size, location and developmental stage of the cysts, their surrounding inflammatory oedema, clinical symptoms/signs (their acuteness and severity) as well as potential risk factors of treatment. On the one hand, care needs to be taken not to "over-treat" as the administration of antihelminthic drugs can cause cerebral oedema and worsen symptoms and, on the other hand, one has to be prepared to extend treatment for some months as the penetration of drugs into cysts can be poor. The follow-up of patients has to be ensured, ideally with neuroimaging, but this may not be available in resource-poor settings $[90,95,117]$. Although treatment has to be flexible, there are some rules of thumb that should be followed. The administration of antihelminthic drugs may elicit or increase pre-existing cerebral oedema and therefore is contraindicated in cases with increased intracranial pressure, subarachnoidal NCC in close proximity to blood vessels and NCC encephalitis (Figure 2). In these conditions, steroids should be administered alone and may later be combined with antihelminthic drugs. In intraparenchymal active NCC without signs of increased intracranial pressure, steroids should be administered simultaneously with antihelminthic treatment, at least for the first week. The antihelminthic drug of choice is albendazole, which unfortunately is not often available in sub-Saharan Africa. The suggested dose is $15 \mathrm{mg} / \mathrm{kg}$ per day for 8-15 days. Praziquantel can also be used to treat NCC, although it is not as effective as albendazole [118], but it can be found in most sub-Saharan countries. Its recommended dose is $50 \mathrm{mg} / \mathrm{kg}$ per day for 15-30 days [90,94,117]. Metabolism of praziquantel and albendazole is increased with simultaneous usage of antiepileptic drugs, in particular phenytoin and carbamazepine, and the levels of praziquantel are reduced when the drug is administered together with steroids. Co-administration with cimetidine may increase the bioavailability of praziquantel $[90,94]$. Alternatively the dose of praziquantel may be increased or its course shortened and repeated. Also, in resource-poor settings, patients may not be particularly compliant with treatment. The best solution would be to keep the patient in hospital for the time of treatment, but due to financial expenses the patient may not agree. To minimise costs an elegant solution may be a high-dose short-term treatment with $100 \mathrm{mg} / \mathrm{kg}$ praziquantel in three divided doses every two hours followed by corticosteroids. This treatment regimen has been demonstrated to be successful in single cyst disease, but unfortunately efficacy could not be demonstrated in patients with multiple cysts, which is the phenotype that prevails in sub-Saharan Africa $[67,119,120]$. Even with normal dosage and course of treatment cure rates with antihelminthic drugs in general seem to be low. In untreated patients, $40 \%$ of cysts are cleared and in treated patients $60 \%$ of cysts disappear after one course of treatment. Furthermore, rebound inflammation may occur after abrupt withdrawal of antihelminthic medication and/or steroids and may be due to overcompensation of the immune system after removal of treatment with anti-inflammatory medication [117].

Steroids should be initiated together with antihelminthic drugs in intraparenchymal disease and ideally should be administered for as long as the patient is symptomatic (e.g. chronic 
progressive headache, acute symptomatic epileptic seizures) but at least for the first days antihelminthic treatment is given. So far steroid doses in the treatment of NCC have not been standardized [121]. Prednisone is recommended at a dosage of $1 \mathrm{mg} / \mathrm{kg}$ per day either p.o. or i.v.. Alternatively, dexamethasone can be used at $12-24 \mathrm{mg} / \mathrm{d}$, maximum of 30 $\mathrm{mg} /$ day, p.o. or i.v.. Metabolism of both drugs may be increased by antiepileptic medication $[90,94]$. Steroids are used in all condition where cerebral oedema is present or may develop. To date there are only four controlled trials of the use of steroids in NCC and all of them were conducted in single enhancing granulomatous lesions (see 2.4.). Treatment regimens consisted of prednisolone $1 \mathrm{mg} / \mathrm{kg}$ for 10 days with a 4-day taper with and without antiepileptic treatment, prednisolone $1 \mathrm{mg} / \mathrm{kg}$ for 7 days with a 3-day taper without antiepileptic treatment and methylprednisolone $1 \mathrm{~g} / 1.72 \mathrm{~m}^{2}$ for 5 days without antiepileptic treatment. All studies showed a decrease in epileptic seizures and three showed a significant clearance of cysts on CT [122-125].

In summary, only confirmed active intraparenchymal and symptomatic (e.g. epileptic seizures) disease requires treatment with triple therapy, i.e. antihelminthic medication, steroids and antiepileptic medication. For antiepileptic treatment see 2.6.2. Once the parasite has gone into the transitional stage, antihelminthic drugs may no longer be needed as the parasite is already attacked and destroyed by the host. Current advice is that the symptomatic patient of the transitional stage should be maintained on symptomatic treatment only, i.e. steroids and antiepileptic medication [126]. There is however some controversy over the topic of treatment of the transitional stage and new results are expected shortly (personal communication with Prof. Hector H. Garcia, Universidad Peruana Cayetano Heredia, Lima, Peru). In inactive symptomatic disease the patient should receive antiepileptic mediation only if seizures are present. If perilesional oedema is obvious, steroids may be beneficial, although there are only anecdotal reports [121]. Treatment of extraparenchymal disease is much more tedious than that of intraparenchymal disease, and in most cases requires lengthy treatment regimens with antihelminthic medication and steroids or operative procedure if cysts are located in the ventricles [117]. For more details refer to the chapter of extraparenchymal NCC...

Furthermore, treatment of affected individuals only represents one facet in the multifaceted approach towards the eradication of NCC. Another important step is the prevention (reducing the number of free-roaming pigs, the vaccination of pigs) and treatment of porcine cysticercosis as well as the treatment of Taenia solium taeniosis (human tapeworm infection; $[47,67,127,128])$. In addition, increasing hygienic standards in affected communities, meat inspections, educating farmers and health education within communities should be top priorities in the fight against NCC. For more details refer to the chapter of ...

\subsubsection{Antiepileptic treatment}

Antiepileptic treatment should be initiated if seizure activity is recurrent, irrespective of whether epileptic seizures occur within the setting of stage- 3 symptomatic cysts or stage-4 calcifications after clearance of the parasite (see 2.2.). According to the latest guidelines of the International League Against Epilepsy [129], treatment should be initiated after the 
first epileptic seizure if seizures are caused by an underlying lesion. In resource-poor settings without access to neuroimaging, an underlying lesion in the context of NCC can only be assumed if certain factors such as neurological signs on examination or a contact history with a tapeworm carrier or pigs are present. In some hospitals, electroencephalography may be available and focal activities on electroencephalograms may help decide when to start treatment.

Antiepileptic medication is limited in sub-Saharan Africa. The mainstay of antiepileptic treatment is phenobarbitone, although phenytoin and carbamazepine can also be found in rural African hospitals, but their supply is often erratic. Valproate is stocked only occasionally, and most times is not delivered through the national pharmacies, but relies on private donations. Dosing and potential side effects of antiepileptic medication available in sub-Saharan Africa are given in Table 1.

\begin{tabular}{|c|c|c|c|c|}
\hline $\begin{array}{l}\text { Antiepileptic } \\
\text { medication } \\
\text { (indication) }\end{array}$ & Starting dose & \begin{tabular}{|l} 
Titration \\
( usual adult \\
maintenance \\
dose)
\end{tabular} & $\begin{array}{l}\text { Side effects (list non- } \\
\text { exhaustive) }\end{array}$ & $\begin{array}{l}\text { Route of } \\
\text { administration }\end{array}$ \\
\hline $\begin{array}{l}\text { Phenobarbitone } \\
\text { (all forms of } \\
\text { epilepsy; may } \\
\text { be tried in } \\
\text { atypical } \\
\text { absences, atonic } \\
\text { and tonic } \\
\text { seizures) }\end{array}$ & $\begin{array}{l}\text { 1. } 30 \mathrm{mg} \text { p.o. } \\
\text { 2. (rapid) } 50 \mathrm{mg} \text { i.v., s.c. or } \\
\text { i.m. every } 6 \mathrm{~h} \text { diluted } 1: 10 \\
\text { with inj. water } \\
\text { 3. (status) } 20 \mathrm{mg} / \mathrm{kg} \text { i.v. } \\
\text { diluted } 1: 10 \text { with inj. water } \\
\text { (start with } 200-400 \mathrm{mg} \text { ) } \\
\text { (maximum rate: } 100 \\
\text { mg/min) }\end{array}$ & $\begin{array}{l}30 \text { mg p.o. } \\
\text { every } 3 \text { days } \\
\text { (long half-life) } \\
(\sim 60-180 \\
\text { mg/day) }\end{array}$ & \begin{tabular}{|l|} 
neurological/psychiatric: \\
fatigue, drowsiness, lethargy, \\
pronounced cognitive decline, \\
learning disabilities, \\
headaches, ataxia, nystagmus, \\
dysarthria, depression, \\
agitation, aggression, \\
hyperkinesia (children), \\
confusion (elderly); other: \\
megaloblastic anaemia (may \\
be treated with folic acid $\left.{ }^{* *}\right)$, \\
constipation, rickets and \\
osteomalacia (vitamin D \\
deficiency**), impotence; \\
vitamin K deficiency** and \\
withdrawal seizures in new- \\
borns; teratogenicity \\
rapid titration in status: \\
respiratory depression \\
\end{tabular} & $\begin{array}{l}\text { oral, i.v., s.c., } \\
\text { i.m. }\end{array}$ \\
\hline $\begin{array}{l}\text { Carbamazepine } \\
\text { (partial (simple } \\
\text { and complex) } \\
\text { and secondary } \\
\text { generalised } \\
\text { tonic-clonic } \\
\text { seizures; some } \\
\text { primary } \\
\text { generalised } \\
\text { seizures; not in } \\
\text { absences and } \\
\text { myoclonic } \\
\text { seizures) }\end{array}$ & $200 \mathrm{mg}$ p.o. & $\begin{array}{l}200 \text { mg p.o. } \\
\text { every 3-5 days } \\
(\sim 800-2000 \\
\text { mg/day })\end{array}$ & \begin{tabular}{|l|} 
skin: from transient \\
erythematous rash \\
(frequent) to Stevens-Johnson \\
syndrome, photosensitivity \\
lupus erythematosus; blood: \\
leucopenia, \\
thrombocytopenia, \\
agranulocytosis, aplastic \\
anaemia; cardiovascular: \\
conduction disturbances, \\
thromboembolism; gastro- \\
intestinal: nausea, vomiting, \\
cholestatic jaundice, hepatitis, \\
constipation, diarrhoea,
\end{tabular} & oral \\
\hline
\end{tabular}




\begin{tabular}{|c|c|c|c|c|}
\hline $\begin{array}{l}\text { Antiepileptic } \\
\text { medication } \\
\text { (indication) }\end{array}$ & Starting dose & \begin{tabular}{|l} 
Titration \\
( usual adult \\
maintenance \\
dose) \\
\end{tabular} & $\begin{array}{l}\text { Side effects (list non- } \\
\text { exhaustive) }\end{array}$ & $\begin{array}{l}\text { Route of } \\
\text { administration }\end{array}$ \\
\hline & & & $\begin{array}{l}\text { anorexia; genito-urinary: renal } \\
\text { failure, proteinuria, } \\
\text { impotence; } \\
\text { neurological/psychiatric: } \\
\text { dizziness, drowsiness, } \\
\text { headache, ataxia, confusion, } \\
\text { agitation, visual disturbances } \\
\text { (double vision often } \\
\text { associated with peak plasma } \\
\text { levels), dyskinesia, } \\
\text { paraesthesia, depression, } \\
\text { activation of psychosis; other: } \\
\text { alopecia, arthralgia, fever, } \\
\text { lymph node enlargement, } \\
\text { gynaecomastia, galactorrhoea, } \\
\text { pulmonary hypersensitivity, } \\
\text { hyponatraemia, oedema, } \\
\text { osteomalacia; teratogenicity; }\end{array}$ & \\
\hline $\begin{array}{l}\text { Phenytoin (all } \\
\text { forms of } \\
\text { epilepsy except } \\
\text { absence seizures } \\
\text { and myoclonic } \\
\text { seizures) }\end{array}$ & $\begin{array}{l}\text { 1. } 300 \mathrm{mg} \text { p.o. } \\
\text { 2. (rapid) } 600 \mathrm{mg} \text { p.o. for } 3 \\
\text { days } \\
\text { 3. (status) } 1.5 \mathrm{~g} \text { i.v. diluted } \\
\text { 1:10 with inj. water (first } 250 \\
\text { mg as bolus over } 10 \\
\text { minutes, next } 500 \mathrm{mg} \text { in } 0.5 \\
\text { to } 6 \text { hours, next } 750 \mathrm{mg} \text { in } 1- \\
24 \text { hours according to clinic) } \\
\text { (maximum rate: } 20 \mathrm{mg} / \mathrm{min} \text { ) }\end{array}$ & $\begin{array}{l}25-50 \mathrm{mg} \text { p.o. } \\
\text { per day } \\
(\sim 200-500 \\
\text { mg/day })\end{array}$ & $\begin{array}{l}\text { skin and gum: gingival } \\
\text { hypertrophy and tenderness, } \\
\text { coarse facies, hirsutism, acne, } \\
\text { rash***, lupus erythematosus, } \\
\text { Stevens-Johnson syndrome, } \\
\text { toxic epidermal necrolysis; } \\
\text { blood: megaloblastic anaemia } \\
\text { (may be treated with folic } \\
\text { acid**) leucopenia, } \\
\text { thrombocytopenia, } \\
\text { agranulocytosis, aplastic } \\
\text { anaemia; gastro-intestinal: } \\
\text { nausea, vomiting, hepatitis, } \\
\text { liver failure; } \\
\text { neurological/psychiatric: } \\
\text { vertigo, double vision, } \\
\text { nystagmus, tremor, confusion, } \\
\text { dizziness, headache, insomnia } \\
\text { dyskinesia; ataxia, slurred } \\
\text { speech, nystagmus and } \\
\text { blurred vision (are signs of } \\
\text { overdosage); peripheral } \\
\text { neuropathy, irreversible } \\
\text { cerebellar atrophy; other: } \\
\text { fever, polyarthritis, } \\
\text { lymphadenopathy, rickets } \\
\text { and osteomalacia (lowered } \\
\text { plasma calcium } \\
\text { concentration); teratogenicity; } \\
\text { rapid titration in status: } \\
\text { cardiac dysrhythmias, } \\
\text { hypotonia }\end{array}$ & $\begin{array}{l}\text { oral, i.v. } \\
\text { (beware of } \\
\text { phlebitis) }\end{array}$ \\
\hline
\end{tabular}




\begin{tabular}{|c|c|c|c|c|}
\hline $\begin{array}{l}\text { Antiepileptic } \\
\text { medication } \\
\text { (indication) }\end{array}$ & Starting dose & \begin{tabular}{|l} 
Titration \\
( usual adult \\
maintenance \\
dose) \\
\end{tabular} & $\begin{array}{l}\text { Side effects (list non- } \\
\text { exhaustive) }\end{array}$ & $\begin{array}{l}\text { Route of } \\
\text { administration }\end{array}$ \\
\hline $\begin{array}{l}\text { Valproate (all } \\
\text { forms of } \\
\text { epilepsy; drug } \\
\text { of choice in } \\
\text { primary } \\
\text { generalised } \\
\text { epilepsy, } \\
\text { generalised } \\
\text { absences and } \\
\text { myoclonic } \\
\text { seizures; may be } \\
\text { tried in atypical } \\
\text { absences, atonic } \\
\text { and tonic } \\
\text { seizures, Salaam } \\
\text { attacks; has got } \\
\text { similar efficacy } \\
\text { to that of } \\
\text { phenytoin and } \\
\text { carbamazepine } \\
\text { in partial } \\
\text { epilepsy) }\end{array}$ & $\begin{array}{l}\text { 1. } 600 \mathrm{mg} \text { p.o. } \\
\text { 2. (status) } 3.6 \mathrm{~g} \text { i.v. diluted } \\
\text { approx. } 1: 10 \text { with inj. water } \\
\text { (first } 1.2 \mathrm{~g} \text { as bolus over } 10 \\
\text { minutes, second } 1.2 \mathrm{~g} \text { as } \\
\text { bolus over } 10 \text { minutes, next } \\
1.2 \mathrm{~g} \text { in } 12-24 \text { hours } \\
\text { according to clinic) } \\
\text { (maximum rate: } 100-200 \\
\text { mg/min) }\end{array}$ & $\begin{array}{l}\text { 150-300 mg p.o. } \\
\text { every } 3 \text { days } \\
(\sim 900-3000 \\
\mathrm{mg} / \mathrm{d})\end{array}$ & $\begin{array}{l}\text { skin: rash, toxic epidermal } \\
\text { necrolysis, Stevens-Johnson } \\
\text { syndrome, vasculitis, } \\
\text { hirsutism, acne; } \\
\text { blood: thrombocytopenia, } \\
\text { inhibition of platelet } \\
\text { aggregation, leucopenia, } \\
\text { pancytopenia, red cell } \\
\text { hypoplasia, fibrinogen } \\
\text { reduction; } \\
\text { gastro-intestinal: nausea, } \\
\text { vomiting, increased appetite } \\
\text { and weight gain, impaired } \\
\text { hepatic function leading } \\
\text { rarely to fatal hepatic } \\
\text { failure****, rarely } \\
\text { pancreatitis****, } \\
\text { hyperammonaemia; } \\
\text { neurological/psychiatric: } \\
\text { ataxia, tremor, dizziness, } \\
\text { sedation (rarely lethargy and } \\
\text { confusion associated with too } \\
\text { high an initial dose), } \\
\text { increased alertness, } \\
\text { occasionally aggression, } \\
\text { hyperactivity and } \\
\text { behavioural disturbances, } \\
\text { extrapyramidal symptoms, } \\
\text { dementia, acute valproate- } \\
\text { induced } \\
\text { encephalopathy******; } \\
\text { other: irregular periods, } \\
\text { amenorrhoea, } \\
\text { gynaecomastia, hearing loss, } \\
\text { Fanconi's syndrome, fatigue, } \\
\text { hair loss, oedema }\end{array}$ & oral, i.v. \\
\hline
\end{tabular}

*has a narrow therapeutic index and the relationship between dose and plasma concentration is non-linear; small dosage increases in some patients may produce large rise in plasma concentration with acute toxic side-effects; a few missed doses or a small change in drug absorption may result in a marked change in plasma concentration.

*** consider vitamin administration together with antiepileptic medication

***discontinue; if mild re-introduce cautiously, but discontinue immediately if recurrence

$* * * *$ withdraw treatment immediately if vomiting, anorexia, jaundice or/and loss of seizure control occurs $* * * * *$ measure plasma amylase in acute abdominal pain

******* withdraw treatment immediately if within the first week of starting medication impairment of consciousness, increased seizure frequency, dysarthria and/or, asterixis occurs

Table 1. Antiepileptic medication available in sub-Saharan Africa: indication, drug loading, titration and maintenance doses as well as side effects (in the order of their availability; adjusted from [67]) 
Epileptic seizures in the context of NCC are of the secondary generalized type, but very often clinical examination does not reveal neurological signs. Therefore, in practice, it is difficult to differentiate epileptic seizure due to NCC from other types of seizures. Given the limited supply of medication, the most appropriate antiepileptic medication for seizures caused by NCC would be carbamazepine which is effective for partial seizures and secondary generalised seizures. It has generally fewer side-effects than phenytoin or the barbiturates, but reversible blurring of vision, dizziness and unsteadiness are dose-related and may be dose-limiting (Table 1). If carbamazepine is absent or if it is not tolerated, phenobarbitone and phenytoin can also be administered. However side effects may limit their use (Table 1). Therefore, if in a patient with normal neurological examination additional tests such as a positive result on Taenia solium cysticercosis antigen serology and/or neuroimaging indicate a focal start of the seizure, the patient should be started on carbamazepine first. As most people with epilepsy in sub-Saharan Africa do not have access to these investigations, treatment has to be started according to the suspected origin of the seizures and based on the experience of the involved physician. Also, phenobarbitone, despite its unpleasant side effect profile, has been shown to be a highly effective drug when it comes to seizure control. Surprisingly, many adults tolerate it fairly well, but its use has to be very restrictive in children and women of child bearing age because of possible cognitive decline and withdrawal seizures in the new-born, respectively (Table 1). A recent study from a Taenia solium cysticercosis endemic area of northern Tanzania showed that compliant people with epilepsy and NCC were well controlled on antiepileptic monotherapy with a trend towards better seizure control under carbamazepine compared to phenobarbitone. However, sample size in the groups was small and a final conclusion as to which of the two drugs leads to better seizure control in people with epilepsy and NCC cannot be drawn with certainty [74].

In addition to choosing the right antiepileptic medication, communication with the patients and their families is vital. The treatment gap for people with epilepsy in sub-Saharan Africa is substantial and it is most important to take its causative factors into consideration when counselling people with epilepsy (see 1.4.). It is also mandatory that patients who are started on antiepileptic medication and their families are informed about potentially ensuing side effects as well as the temporary nature of some of them in order to enhance compliance with medication. Follow-up appointments in short interval are advisable in the early phase of antiepileptic treatment. When informing patients about their treatment it has to be emphasized that withdrawal seizures can occur when stopping antiepileptic medication abruptly and that once their seizures abate the medication still has to be continued until the physician decides to withdraw the medication. There are no guidelines as to withdrawal of antiepileptic mediation in the context of NCC and therefore this has to be decided on a caseto-case basis. Usually withdrawal is considered when the epilepsy is in remission, i.e. the patient has to be seizure free for two years, although one year may be considered enough in resource-poor settings. Predictors for remaining seizure-free after withdrawal of antiepileptic medication seem to be normal neurological examination and use of carbamazepine prior to withdrawal [130], indicating outcome after drug withdrawal may be favourable in people with epilepsy and NCC. However, longitudinal studies on withdrawal of antiepileptic medication in people with epilepsy and NCC in sub-Saharan Africa have not 
been performed so far, but would definitely be needed to be able to develop guidelines on withdrawal of antiepileptic medication in this population.

\subsubsection{Treatment in the absence of neuroimaging}

The majority of patients in resource-poor settings have neither got access to neuroimaging nor to Taenia solium cysticercosis immunodiagnostic tests. Although positive results on Taenia solium cysticercosis antigen-ELISA may indicate active disease [131], treatment with antihelminthic medication must not be initiated on the basis of serology alone as cyst stage and presence of oedema cannot be estimated. Oedema can potentially be aggravated by antihelminthic medication resulting in deterioration of the patient's condition and, in the worst case, death may ensue caused by cerebral herniation leading to compression of the brainstem with severe compromise of vital functions. Therefore, I strongly suggest that in the absence of neuroimaging patients should be treated symptomatically only, i.e. anti-pain medication and antiepileptic drugs (see 2.5.2.).

The administration of steroids as symptomatic treatment in patients with signs and symptoms of increased intracranial pressure, such as chronic progressive headache in the context of suspected but not imaging-confirmed NCC, is debatable and has to be decided on an individual basis. A classical scenario where steroid administration may be advisable is in patients with acute symptomatic seizures who come from a Taenia solium cysticercosis endemic area. High doses of steroids may be started in these patients and tapered once symptoms abate. At the same time antiepileptic medication should be started on which the patient will be maintained until fit for withdrawal (see 2.5.2.). In this context, it is however crucial to exclude the most important differential diagnoses such as cerebral malaria, bacterial and tuberculous meningitis as well as encephalitis, among others, for which a spinal tap is necessary. The result of cerebrospinal fluid analysis is usually unequivocal for bacterial meningitis and in that case steroids are not to be started without antibacterial treatment. The result of cerebrospinal fluid analysis in tuberculous meningitis and viral encephalitis may be similar to that in NCC (although most patients with intraparenchymal NCC show normal results on cerebrospinal fluid; see 2.4.) with an unspecific medium increase in cell count and no major other obvious abnormalities, especially in a resourcepoor setting where protein and glucose often are not measured. The eosinophils may be elevated in NCC, but this is not mandatory. Therefore differential diagnosis may prove difficult, but a trial of steroids will not harm patients with tuberculous meningitis or viral encephalitis as brain oedema may be present and administration of steroids to these patients may actually improve their symptoms $[132,133]$.

Even after satisfactory symptomatic treatment the question remains whether withholding antihelminthic treatment in patients with NCC will have disadvantages in terms of cyst clearance or seizure control. Results are controversial. Garcia et al. showed that treatment with albendazole in addition to antiepileptic medication significantly cleared the parasite and reduced seizure frequency, especially those with generalisation, when compared to the control group that received antiepileptic medication only [134]. In contrast, in another study the same combination of albendazole and antiepileptic treatment in people with NCC was 
not superior to therapy with antiepileptic drugs alone. The combination treatment led to increased hospital admission, increased seizure frequency, more cases of encephalopathy and deaths. A greater proportion of lesions calcified compared to the group that was treated with antiepileptic drugs alone, in which more lesions resolved completely [135].

In summary, treatment of NCC in the absence of neuroimaging has to be decided on an individual basis and depends on clinical symptoms and/or signs, whether acute or chronic, and on the physician's experience as well as local practice. Most patients with NCC can be maintained on antiepileptic medication alone, but steroid application may be considered in the severely ill patient bearing in mind the implication of potential differential diagnoses.

\section{Conclusions and outlook}

This chapter demonstrates clearly the importance of epileptic seizures/epilepsy and NCC for sub-Saharan Africa in terms of prevalence and burden of each of the two disorders, but it also emphasizes NCC as an important cause of acute symptomatic seizures and secondary epilepsy in many African countries. Taenia solium cysticercosis is a potentially eradicable disease and successful implementation of treatment of human taeniosis and porcine cysticercosis (please refer to other chapters in the book) as well as enforcement of hygienic measure, such as building of latrines and hand washing after toilet use, among others, may prevent many cases of epileptic seizures/epilepsy and therefore reduce individual suffering as well as socioeconomic losses to African societies. Although eradication of the disease has to be the ultimate aim, treatment of affected individuals for now should be in the forefront of activities of African physicians who attend to people with epileptic seizures/epilepsy. I have suggested how people with epileptic seizures/epilepsy and/or NCC in resource-poor settings should be approached, but want to emphasize that this is my personal opinion/experience based on many years of work as a trained neurologist in sub-Saharan Africa. Conveying my own opinion in this chapter my aim was to stimulate discussion across disciplines and nations. Hopefully national and international stakeholders, such as the ministries of health of African countries and The World Health Organization, have by now become aware that NCC and the ensuing epilepsy in sub-Saharan African represent a "silent epidemic". Affected people deserve standardized treatment maximizing its benefits but at the same time minimizing its drawbacks. In that sense I am hopeful that in the near future guidelines on how to treat people with epilepsy and/or NCC will be decided by an expert-led commission and enforced as standard of care in sub-Saharan countries by the respective national and internal stakeholders.

\section{List of abbreviations}

CT; computed tomography

CWGESA; Cysticercosis Working Group in Eastern and Southern Africa

FLAIR; fluid attenuated inversion recovery

HIV/AIDS; human immunodeficiency virus/acquired immunodeficiency syndrome

MRI; magnetic resonance imaging 
NCC; neurocysticercosis

\section{Author details}

Andrea Sylvia Winkler*

Department of Neurology, Klinikum rechts der Isar, Technical University Munich, Munich, Germany

\section{Acknowledgement}

I am extremely grateful to the patients of the Epilepsy Clinics of Haydom Lutheran Hospital (northern Tanzania) and Mahenge Hospital (southern Tanzania) for helping me gain all my experience which a good part of this book chapter is based on. I am further indebted to all my African, European and Canadian colleagues and friends who have always encouraged me to take up "neurology of sub-Saharan Africa" as my special field of research. I am also extremely thankful to the German Research Foundation (DFG) and the Bill and Melinda Gates foundation for supporting further work into the subject of epilepsy and NCC.

\section{References}

[1] International League Against Epilepsy (ILAE). Commission on Epidemiology and Prognosis of the International League Against Epilepsy. Guidelines for epidemiologic studies on epilepsy. Epilepsia 1993; 34: 592-596.

[2] Senanayake N, Román GC. Epidemiology of epilepsy in developing countries. Bulletin of the World Health Organization 1993; 71: 247-258.

[3] Edwards T, Scott AG, Munyoki G, Odera V, Chengo E, Bauni E, Kwasa T, Sander LW, Neville BG, Newton CR. Active convulsive epilepsy in a rural district of Kenya: a study of prevalence and possible risk factors. The Lancet Neurology 2008; 7: 50-56.

[4] Aall-Jilek LM. Epilepsy in the Wapogoro tribe in Tanganyika. Acta Psychiatrica Scandinavica $1965 ;$ 41: 57-86.

[5] Osuntokun BO. The pattern of neurological illness in tropical Africa. Experience at Ibadan, Nigeria. Journal of the Neurological Sciences 1971; 12: 417-442.

[6] Preux PM, Druet-Cabanac M. Epidemiology and aetiology of epilepsy in sub-Saharan Africa. The Lancet Neurology 2005; 4: 21-31.

[7] Forsgren L. Estimations of the prevalence of epilepsy in sub-Saharan Africa. The Lancet Neurology 2008; 7: 21-22.

[8] Forsgren L, Beghi E, Oun A, Sillanpää M. The epidemiology of epilepsy in Europe - a systematic review. European Journal of Neurology 2005; 12: 245-253.

[9] Rwiza HT, Kilonzo GP, Haule J, Matuja WBP, Mteza I, Mbena P, Kilima PM, Mwaluko G, Mwang'ombola R, Mwanijande F, Rweyemamu G, Matowo A, Jilek-Aall LM. Prevalence and incidence of epilepsy in Ulanga, a rural Tanzanian district: a community-based study. Epilepsia 1992; 33: 1051-1056.

\footnotetext{
${ }^{*}$ Corresponding Author
} 
[10] Mosser P, Schmutzhard E, Winkler AS. The pattern of epileptic seizures in rural Tanzania. Journal of the Neurological Sciences 2007; 258: 33-38.

[11] Winkler AS, Mosser P, Schmutzhard E. Neurological disorders in rural Africa: a systematic approach. Tropical Doctor 2009a; 39: 102-104.

[12] Winkler AS, Kerschbaumsteiner K, Stelzhammer B, Meindl M, Kaaya J, Schmutzhard E. Prevalence, incidence and clinical characteristics of epilepsy - a community-based doorto-door study in northern Tanzania. Epilepsia 2009b; 50: 2310-2313.

[13] Tekle-Haimanot R. The pattern of epilepsy in Ethiopia: analysis of 468 cases. Ethiopian Medical Journal 1984; 22: 113-118.

[14] Tekle-Haimanot R, Abebe M, Gebre-Mariam A, Forsgren L, Heijbel J, Holmgren G, Ekstedt J. Community-based study of neurological disorders in rural Central Ethiopia. Neuroepidemiology 1990; 9: 263-277.

[15] Osuntokun BO, Adeuja AO, Nottidge VA, Bademosi O, Olumide A, Ige O, Yaria F, Bolis CL, Schoenberg BS. Prevalence of the epilepsies in Nigerian Africans: a community-based study. Epilepsia 1987; 28: 272-79.

[16] Birbeck G. Neurologic disease in a rural Zambian hospital. Tropical Doctor 2001a; 31: 82-85.

[17] Birbeck G. Seizures in rural Zambia. Epilepsia 2001b; 41: 277-281.

[18] Birbeck G, Kalichi EMN. Epilepsy prevalence in rural Zambia: a door-to-door survey. Tropical Medicine and International Health 2004; 9: 92-95.

[19] Dent W, Helbok R, Matuja WBP, Scheunemann S, Schmutzhard E. Prevalence of active epilepsy in a rural area in South Tanzania: a door-to-door survey. Epilepsia 2005; 46: 1963-1969.

[20] International League Against Epilepsy (ILAE). Commission on Classification and Terminology of the International League Against Epilepsy. Proposal for revised clinical and electroencephalographic classification of epileptic seizures. Epilepsia 1981; 22: 489501.

[21] International League Against Epilepsy (ILAE). Commission on Classification and Terminology of the International League Against Epilepsy. Proposal for classification of epilepsies and epileptic syndromes. Epilepsia 1985; 26: 268-278.

[22] International League Against Epilepsy (ILAE). Commission on Classification and Terminology of the International League Against Epilepsy. Proposal for revised classification of epilepsies and epileptic syndromes. Epilepsia 1989; 30: 389-399.

[23] World Health Organization 2001. The world health report 2001. http://www.who.int/whr/2001/en/whr01_en.pdf Last accessed July 2012

[24] Birbeck GL. Revising and refining the epilepsy classification system: Priorities from a developing world perspective. Epilepsia 2012; 53(Suppl 2):18-21.

[25] Winkler AS, Schaffert M, Schmutzhard E. Epilepsy in resource poor countries suggestion of an adjusted classification. Epilepsia 2007; 48: 1029-1030.

[26] Winkler AS, Schaffert M, Schmutzhard E. The pattern of epilepsy in a rural African hospital - an approach adapted to local circumstances. Tropical Doctor 2009c; 39: 44-47.

[27] Fröscher W, Vassella F, Hufnagel A, editors. Die Epilepsien. Stuttgart: Schattauer; 2004.

[28] Reutens DC, Berkovic SF. Idiopathic generalized epilepsy of adolescence: are the syndromes clinically distinct? Neurology 1995; 45: 1469-1476. 
[29] Wolf P. Historical aspects of idiopathic generalized epilepsies. Epilepsia 2005; 46: 7-9.

[30] Couper J. Prevalence of childhood disability in rural KwaZulu-Natal. South African Medical Journal 2002; 92: 549-552.

[31] Ashwal S, Russman BS, Blasco PA, Miller G, Sandler A, Shevell M, Stevenson R; Quality Standards Subcommittee of the American Academy of Neurology; Practice Committee of the Child Neurology Society. Practice parameter: diagnostic assessment of the child with cerebral palsy: report of the Quality Standards Subcommittee of the American Academy of Neurology and the Practice Committee of the Child Neurology Society. Neurology 2004; 62: 851-863.

[32] Aneja S, Ahuja B, Taluja V, Bhatia VK. Epilepsy in children with cerebral palsy. Indian Journal of Pediatrics 2001; 68: 111-115.

[33] Everitt AD, Sander JWAS. Classification of the epilepsies. Time for a change? European Journal of Neurology 1999; 42: 1-10.

[34] Scott RA, Lhatoo SD, Sander JWAS. The treatment of epilepsy in developing countries: where do we go from here? Bulletin of the World Health Organization 2001; 79: 344351.

[35] Ngugi AK, Bottomley C, Kleinschmidt I, Sander JW, Newton CR. Estimation of the burden of active and life-time epilepsy: a meta-analytic approach. Epilepsia 2010; 51: 883-890.

[36] Meyer AC, Dua T, Ma J, Saxena S, Birbeck G. Global disparities in the epilepsy treatment gap: a systematic review. Bulletin of the World Health Organization 2010; 88: 260-266.

[37] Mbuba CK, Ngugi AK, Fegan G, Ibinda F, Muchohi SN, Nyundo C, Odhiambo R, Edwards T, Odermatt P, Carter JA, Newton CR. Risk factors associated with the epilepsy treatment gap in Kilifi, Kenya: a cross-sectional study. The Lancet Neurology 2012; 11: 688-696.

[38] Winkler AS. Measuring the epilepsy treatment gap in sub-Saharan Africa. The Lancet Neurology 2012; 11. 655-657.

[39] Winkler AS, Mayer M, Schnaitmann S, Ombay M, Mathias B, Schmutzhard E, Jilek-Aall L. Belief systems of epilepsy and attitudes towards people living with epilepsy in a rural community of northern Tanzania. Epilepsy \& Behavior 2010a; 19: 596-601.

[40] Winkler AS, Mayer M, Ombay M, Mathias B, Schmutzhard E, Jilek-Aall L. Attitudes towards African traditional medicine and Christian spiritual healing regarding treatment of epilepsy in a rural community of northern Tanzania. African Journal of Traditional, Complementary and Alternative Medicines 2010b; 7: 162-170.

[41] Jilek-Aall L. Morbus sacer in Africa: some religious aspects of epilepsy in traditional cultures. Epilepsia 1999; 40: 382-386.

[42] Birbeck G, Chomba E, Atadzhanov M, Mbewe W, Haworth A. The social and economic impact of epilepsy in Zambia: a cross-sectional study. The Lancet Neurology 2007; 6: 39-44.

[43] Sander JWAS, Shovron SD. Epidemiology of the epilepsies. Neuroepidemiology 1996; 61: 433-443.

[44] Jallon P. Epilepsy in developing countries. Epilepsia 1997; 38: 1143-1151. 
[45] Del Brutto OH. Helminthic infections of the central nervous system. In: Noseworthy JH (ed). Neurological therapeutic principles and practice. Abingdon, Oxon (UK): Informa Health Care; 2006. pp 1133-1152.

[46] Wallin M, Kurtzke J. Neurocysticercosis in the United States: review of an important emerging infection. Neurology 2004; 63: 1559-1564.

[47] Willingham AL III, Harrison LJ, Fèvre EM, Parkhouse ME. Inaugural meeting of the Cysticercosis Working Group in Europe. Emerging Infectious Diseases 2008; 14: e2.

[48] Del Brutto OH. A review of cases of human cysticercosis in Canada. Canadian Journal of Neuroscience 2012a: 39: 319-22.

[49] Del Brutto OH. Neurocysticercosis among international travelers. Journal of Travel Medicine 2012b; 19: 112-17.

[50] Del Brutto OH. Neurocysticercosis in Western Europe: a re-emerging disease? Acta Neurologica Belgica 2012c; April 18 [Epub ahead of print]

[51] Fleury A, Gomez T, Alvarez I, Meza D, Huerta M, Chavarria A, Carrillo Mezo RA, Lloyd C, Dessein A, Preux PM, Dumas M, Larralde C, Sciutto E, Fragoso G. High prevalence of calcified silent neurocysticercosis in a rural village of Mexico. Neuroepidemiology 2003; 22: 139-145.

[52] Carabin H, Millogo A, Praet N, Hounton S, Tarnagda Z, Ganaba R, Dorny P, Nitiéma P, Cowan LD; Evaluation du Fardeau Economique de la Cysticercose Au Burkina Faso (EFECAB). Seroprevalence to the antigens of Taenia solium cysticercosis among residents in three villages in Burkina Faso: a cross-sectional study. PLoS Neglected Tropical Diseases 2009; 3: e555.

[53] Kanobana K, Praet N, Kabwe C, Dorny P, Lukanu P, Madinga J, Mitashi P, Verwijs M, Lutumba P, Polman K. High prevalence of Taenia solium cysticercosis in a village community of Bas-Congo, Democratic Republic of Congo. International Journal of Parasitology 2011; 41: 1015-1018.

[54] Mwape KE, Phiri IK, Praet N, Muma JB, Zulu G, Van den Bossche P, de Deken R, Speybroeck N, Dorny P, Gabriël S. Taenia solium infections in a rural area of Eastern Zambia-a community based study. PLoS Neglected Tropical Diseases 2012; 6: e1594

[55] Nitiéma P, Carabin H, Hounton S, Praet N, Cowan LD, Ganaba R, Kompaoré C, Tarnagda Z, Dorny P, Millogo A, Efécab. Prevalence case-control study of epilepsy in three Burkina Faso villages. Acta Neurologica Scandinavica 2012; 126: 270-278.

[56] Ndimubanzi PC, Carabin H, Budke CM, Nguyen H, Qian YJ, Rainwater E, Dickey M, Reynolds S, Stoner JA. A systematic review of the frequency of neurocyticercosis with a focus on people with epilepsy. PLoS Neglected Tropical Diseases 2010; 4: e870.

[57] World Bank 2011.

http://data.worldbank.org/sites/default/files/adi_2011-web.pdf Last accessed July 2012

[58] Carabin H, Ndimubanzi PC, Budke CM, Nguyen H, Qian Y, Cowan LD, Stoner JA, Rainwater E, Dickey M. Clinical manifestations associated with neurocysticercosis: a systematic review. PLoS Neglected Tropical Diseases 2011; 5: e1152.

[59] De Almeida SM, Torres LFB. Neurocysticercosis-retrospective study of autopsy reports, a 17-year experience. Journal of Community Health 2011; 36: 698-702.

[60] WHO 2010. Working to overcome the global impact of neglected tropical diseases. First WHO report on neglected tropical diseases. 
http://whqlibdoc.who.int/publications/2010/9789241564090_eng.pdf

[61] World Atlas 2010.

http://www.worldatlas.com/aatlas/populations/ctypopls.htm "Last accessed July 2012

[62] Ramos-Zúñiga R, Pérez-Gómez HR, Jáuregui-Huerta F, López-Hernández MD, ValeraLizárraga JE, Paz-Vélez G, Becerra-Valdivia A. Incidental Consequences of Antihelmintic Treatment in the Central Nervous System. World Neurosurgery 2012 Feb 10 [Epub ahead of print]

[63] Johnson RB. Potential hazard of mass praziquantel use. American Journal of Medicine 1986; 80: A88.

[64] Torres JR, Noya O, de Noya BA, Mondolfi A. Seizures and praziquantel. A case report. Revista do Instituto de Medicina Tropical São Paulo. 1988; 30: 433-436.

[65] Flisser A, Madrazo I, Plancarte A, Schantz P, Allan J, Craig P, Sarti E. Neurological symptoms in occult neurocysticercosis after single taeniacidal dose of praziquantel. The Lancet. 1993; 342: 748.

[66] Garcia HH, Gonzalez I, Mija L. Neurocysticercosis uncovered by single-dose albendazole. New England Journal of Medicine 2007; 356: 1277-1278.

[67] Winkler AS. Neurocysticercosis in sub-Saharan Africa: A review of prevalence, clinical characteristics, diagnosis and management. Pathogens \& Global Health 2012 (in print).

[68] Mafojane NA, Appleton CC, Krecek RC, Michael LM, Willingham AL $3^{\text {rd. The current }}$ status of neurocysticercosis in eastern and southern Africa. Acta Tropica 2003; 87: 25-33.

[69] Zoli A, Shey-Njila O, Assana E, Nguekam JP, Dorny P, Brandt J, Geerts F. Regional status, epidemiology and impact of Taenia solium cysticercosis in western and central Africa. Acta Tropica 2003a 87: 35-42.

[70] Zoli AP, Nguekam JP, Shey-Njila O, Nsame Nforninwe D, Speybroeck N, Ito A, Sato MO, Dorny P, Brandt J, Geerts S. Neurocysticercosis and epilepsy in Cameroon. Transactions of the Royal Society of Tropical Medicine and Hygiene 2003b; 97: 683-686.

[71] Quet F, Guerchet M, Pion SDS, Ngoungou EB, Nicoletti A, Preux PM. Meta-analysis of the association between cysticercosis and epilepsy in Africa. Epilepsia 2010; 51: 830-837.

[72] Campbell CD, Farrell VJR. Brain scans, epilepsy and cerebral cysticercosis. South African Medical Journal 1987; 72: 885-886.

[73] Winkler AS, Blocher J, Auer H, Gotwald T, Matuja W, Schmutzhard E. Epilepsy and neurocysticercosis in rural Tanzania - an imaging study. Epilepsia 2009d; 50: 987-993.

[74] Blocher J, Schmutzhard E, Wilkins PP, Gupton P, Schaffert M, Auer H, Gotwald T, Matuja W, Winkler AS. A cross-sectional study of people with epilepsy and neurocysticercosis: clinical characteristics and diagnostic approaches. PLoS Neglected Tropical Diseases 2011; 5: e1185.

[75] Rigatti M, Trevisol-Bittencourt PC. Causes of late-onset epilepsy in an epilepsy clinic of Santa Catarina-Southern Brazil. Arquivos de Neuro-Psiquiatria 1999; 57: 787-792.

[76] Medina MT, Rosas E, Rubio-Donnadieu F, Sotelo J. Neurocysticercosis as the main cause of late-onset epilepsy in Mexico. Archives of Internal Medicine 1990; 150: 325-327.

[77] Del Brutto OH, Santibáñez R, Idrovo L, Rodrìguez S, Díaz-Calderón E, Navas C, Gilman RH, Cuesta F, Mosquera A, Gonzalez AE, Tsang VC, García HH. Epilepsy and neurocysticercosis in Atahualpa: a door-to-door survey in rural coastal Ecuador. Epilepsia 2005; 46: 583-587. 
[78] Nicoletti A, Bartoloni A, Sofia V, Bartalesi F, Chavez JR, Osinaga R, Paradisi F, Dumas JL, Tsang VC, Reggio A, Hall AJ. Epilepsy and neurocysticercosis in rural Bolivia: a population-based survey. Epilepsia 2005; 46: 1127-1132.

[79] Mitchell WG, Crawford TO. Intraparenchymal cerebral cysticercosis in children: diagnosis and treatment. Pediatrics 1988; 82: 76-82.

[80] Thomson AJ. Neurocysticercosis-experience at the teaching hospitals of the University of Cape Town. South African Medical Journal 1993; 83: 332-334.

[81] Ferreira LS, Zanardi VA, Scotoni AE, Li LM, Guerreiro MM. Childhood epilepsy due to neurocysticercosis: a comparative study. Epilepsia 2001; 42: 1438-1444.

[82] Singhi P, Singhi S. Neurocysticercosis in children. Journal of Child Neurology 2004; 19: 482-492.

[83] Sáenz B, Ruíz-Garcia M, Jiménez E, Hernández-Aguilar J, Suastegui R, Larralde C, Sciutto E, Fleury A. Neurocysticercosis: clinical, radiologic, and inflammatory differences between children and adults. The Pediatric Infectious Disease Journal 2006; 25: 801-803.

[84] Foyaca-Sibat H, Ibanez-Valdes L de F. Intraventricular neurocysticercosis in HIV positive patients. International Journal of Neurology, 2003a; 2(1).

http://www.ispub.com/journal/the_internet_journal_of_neurology/volume_2_number_1_

37/article/intraventricular_neurocysticercosis_in_hiv_positive_patients.html Last accessed July 2012

[85] Foyaca-Sibat H, Ibanez-Valdes L de F. Neurocysticercosis in HIV-positive patients. International Journal of Infectious Diseases 2003b; 2(2).

http://www.ispub.com/journal/the-internet-journal-of-infectious-diseases/volume-2-

number-2/neurocysticercosis-in-hiv-positive-patients.html Last accessed July 2012

[86] Jessurun J, Barron-Rodriguez LP, Fernandez-Tinoco G, Hernandez-Avila M. The prevalence of invasive amebiasis is not increased in patients with AIDS. AIDS 1992; 6: 307-309.

[87] Parija SC, Gareesh AR. A serological study of cysticercosis in people with HIV. Revista do Instituto de Medicina Tropical de São Paulo 2009; 51: 185-189.

[88] Carabin H, Krecek RC, Cowan LD, Michael L, Foyaca-Sibat H, Nash T, Willingham AL. Estimation of the cost of Taenia solium cysticercosis in Eastern Cape Province, South Africa. Tropical Medicine and International Health 2006; 11: 906-916.

[89] Praet N, Speybroeck N, Manzanedo R, Berkvens D, Nsame Nforninwe D, Zoli A, Quet F, Preux PM, Carabin H, Geerts S. The disease burden of Taenia solium cysticercosis in Cameroon. PLoS Neglected Tropical Diseases 2009; 3: e406.

[90] Serpa JA, Yancey LS, White AC Jr. Advances in the diagnosis and management of neurocysticercosis. Expert Review of Anti-Infective Therapy 2006; 4: 1051-1061.

[91] Davis LE. Neurocysticercosis. In: Power C, Johnson RT (eds). Emerging neurological infections. Boca Raton: Taylor \& Francis; 2005. pp 261-287.

[92] Singh MK, Garg RK, Nath G, Verma DN, Misra S. Single small enhancing computed tomographic $(\mathrm{CT})$ lesions in Indian patients with new-onset seizures: a prospective follow-up in 75 patients. Seizure. 2001; 10: 573-578. 
[93] Singh G, Rajshekhar V, Murthy JMK, S. Prabhakar S, Modi M, Khandelwal N, Garcia HH. A diagnostic and therapeutic scheme for a solitary cysticercus granuloma. Neurology 2010; 75: 2236-2245.

[94] Mansur MM 2010. Cysticercosis. http://emedicine.medscape.com/article/215589-overview Last accessed July 2012

[95] Nash TE, Singh G, White AC, Rajshekhar V, Loeb JA, Proaño JV, Takayanagui OM, Gonzalez AE, Butman JA, DeGiorgio C, Del Brutto OH, Delgado-Escueta A, Evans CA, Gilman RH, Martinez SM, Medina MT, Pretell EJ, Teale J, Garcia HH. Treatment of neurocysticercosis: current status and future research needs. Neurology 2006; 67: 11201127.

[96] White AC. Why are there seizures in neurocysticercosis: Is it in the genes? The Journal of Infectious Diseases 2010; 202: 1152-1153.

[97] Nash TE, Del Brutto OH, Butman JA, Corona T, Delgado-Escueta A, Duron RM, Evans CA, Gilman RH, Gonzalez AE, Loeb JA, Medina MT, Pietsch-Escueta S, Pretell EJ, Takayanagui OM, Theodore W, Tsang VC, Garcia HH. Calcific neurocysticercosis and epileptogenesis. Neurology 2004; 62: 1934-1938.

[98] Cruz ME, Schantz PM, Cruz I, Espinosa P, Preux PM, Cruz A, Benitez W, Tsang VCW, Fermoso J, Dumas M. Epilepsy and neurocysticercosis in an Andean community. International Journal of Epidemiology 1999; 28: 799-803.

[99] Mishra D. Cysticercosis headache: an important differential of childhood headache disorder in endemic countries. Headache 2007; 47: 301-302.

[100] Forlenza OV, Filho AH, Nobrega JP, dos Ramos Machado L, de Barros NG, de Camargo CH, da Silva MF. Psychiatric manifestations of neurocysticercosis: a study of 38 patients from a neurology clinic in Brazil. Journal of Neurology, Neurosurgery and Psychiatry 1997; 62: 612-616.

[101] Ciampi de Andrade D, Rodriques CL, Abraham R, Castro LH, Livramento JA, Machado LR, Leite CC, Caramelli P. Cognitive impairment and dementia in neurocysticercosis: a cross-sectional controlled study. Neurology 2010; 74: 1288-1295.

[102] Wallin MT, Pretell EJ, Bustos JA, Caballero M, Alfaro M, Kane R, Wilkin J, Sullivan C, Fratto T, Garcia HH. Cognitive changes and quality of life in neurocysticercosis: a longitudinal study. PLoS Neglected Infectious Diseases 2012; 6: e1493.

[103] Morales NM, Agapejev S, Morales RR, Padula NA, Lima MM. Clinical aspects of neurocysticercosis in children. Pediatric Neurology 2000; 22: 287-291.

[104] Antoniuk S, Bruck I, Santos LH, Souza LP, Fugimura S. Neurocysticercosis in children: clinical study and follow-up of 112 patients. Revista de Neurologia 2006; 42(suppl 3): S97-101.

[105] Sotelo J, Del Brutto OH. Review of neurocysticercosis. Neurosurgical Focus 2002; 12: e1.

[106] Pal DK, Carpio A, Sander JWAS. Neurocysticercosis and epilepsy in developing countries. Journal of Neurology, Neurosurgery and Psychiatry 2000; 68: 137-143.

[107] Del Brutto OH, Rajshekhar V, White AC Jr, Tsang VC, Nash TE, Takayanagui OM, Schantz PM, Evans CA, Flisser A, Correa D, Botero D, Allan JC, Sarti E, Gonzalez AE, Gilman RH, Garcia HH. Proposed diagnostic criteria for neurocysticercosis. Neurology 2001; 57: 177-183. 
[108] Dorny P, Brandt J, Zoli A, Geerts S. Immunodiagnostic tools for human and porcine cysticercosis. Acta Tropica 2003; 87: 79-86.

[109] Del Brutto OH. Neurocysticercosis. Seminars in Neurology 2005; 25: 243-251.

[110] Winkler AS, Willingham AL, Sikasunge CS, Schmutzhard E. Epilepsy and neurocysticercosis in sub-Saharan Africa. The Middle European Journal of Medicine 2009e; 121(suppl 3): 3-12.

[111] Abraham R, Livramento JA, Leite CDA, Pardini AX, Vaz AJ, Machado Lidos R. Neurocysticercosis: relationship between Taenia antigen levels in CSF and MRI. Arquivos de Neuropsiquiatrica 2010; 68: 7-11.

[112] Praet N, Rodriguez-Hidalgo R, Speybroeck N, Ahounou S, Benitez-Ortiz W, Berkvens D, Hul AV, Barrionuevo-Samaniego M, Saegerman C, Dorny P. Infection with versus exposure to Taenia solium: what do serological test results tell us? American Journal of Tropical Medicine and Hygiene 2010; 83: 413-415.

[113] Almeida CR, Ojopi EP, Nunes CM, Machado LR, Takayanagui OM, Livramento JA, Abraham R, Gattaz WF, Vaz AJ, Dias-Neto E. Taenia solium DNA is present in cerebrospinal fluid of neurocysticercosis patients and can be used for diagnosis. European Archives of Psychiatry and Clinical Neurosciences 2006; 56: 307-310.

[114] Hernández M, Gonzalez LM, Fleury A, Saenz B, Parkhouse RM, Harrison LJ, Garate T, Sciutto E. Neurocysticercosis: detection of Taenia solium DNA in human cerebrospinal fluid using a semi-nested PCR based on HDP2. Annals of Tropical Medicine and Parasitology 2008; 102: 317-323.

[115] Chang KH, Han MH. MRI of CNS parasitic disease. Journal of Magnetic Resonance Imaging 1998; 8: 297-307.

[116] Del Brutto OH, Wadia NH, Dumas M, Cruz M, Tsang VCW, Schantz PM. Proposal of diagnostic criteria for human cysticercosis and neurocysticercosis. Journal of the Neurological Sciences 1996; 142: 1-6.

[117] Nash TE, Garcia HH. Diagnosis and treatment of neurocysticercosis. Nature Reviews Neurology 2011; 7: 584-94.

[118] Del Brutto OH, Roos KL, Coffey CS, Garcia HH. Meta-analysis: Cysticidal drugs for neurocysticercosis: albendazole and praziquantel. Annals of Internal Medicine 2006; 145: 43-51.

[119] Corona T, Lugo R, Medina R, Sotelo J. Single-day praziquantel therapy for neurocysticercosis. New England Journal of Medicine 1996; 334: 125.

[120] Pretell EJ, Garcia HH, Gilman RH, Saavedra H, Martinez M; The Cysticercosis Working Group in Peru. Failure of one-day praziquantel treatment in patients with multiple neurocysticercosis lesions. Clinical Neurology and Neurosurgery 2001; 103: 175-177.

[121] Nash TE, Mahanty S, Garcia HH; Cysticercosis Group in Peru. Corticosteroid use in neurocysticercosis. Expert Review of Neurotherapeutics 2011; 11: 1175-1183.

[122] Mall RK, Agarwal A, Garg RK, Kar AW, Shukla R. Short course of prednisolone in Indian patients with solitary cysticercus granuloma and new onset seizures. Epilepsia 2003; 44: 1397-1401. 
[123] Garg RK, Potluri N, Kar AM, Singh MK, Shukla R, Agrawal A, Verma R. Short course of prednisolone in patients with cysticercus granuloma: a double blind placebo controlled trial. Journal of Infection 2006; 53: 65-69.

[124] Prakash S, Garg RK, Kar AM, Shukla R, Agarwal A, Verma R, Singh MK. Intravenous methyl prednisolone in patients with solitary cysticercus granuloma: a random evaluation. Seizure 2006; 15; 328-323.

[125] Kishore D, Misra S. A short course of oral prednisolone on disappearance of lesion and seizure recurrence in patients of solitary cysticercus granuloma with single small enhancing CT lesion: an open label randomized prospective study. Journal of the Association of Physicians of India 2007; 55: 419-424.

[126] Carpio A. Neuroimaging in Neurocysticercosis. 2012.

http//emedicine.medscape.com/article/1168784-differential Last accessed July 2012

[127] Gonzalez AE, Gauci CG, Barber D, Gilman RH, Tsang VC, Garcia HH, Verastegui M, Lightowlers MW. Short report: vaccination of pigs to control human neurocysticercosis. American Journal of Tropical Medicine and Hygiene 2005; 72: 837-839.

[128] Pawlowski ZS. Control of neurocysticercosis by routine medical and veterinary services. Transactions of the Royal Society of Tropical Medicine and Hygiene 2008; 102: 228-232.

[129] Fisher RS, van Emde Boas W, Blume W, Elger C, Genton P, Lee P, Engel Jr J. Epileptic seizures and epilepsy: definitions proposed by the International League Against Epilepsy (ILAE) and the International Bureau for Epilepsy (IBE). Epilepsia 2005; 46: 470-472.

[130] Lossius MI, Hessen E, Mowinckel P, Stavem K, Erikssen J, Gulbrandsen P, Gjerstad L. Consequences of antiepileptic drug withdrawal: a randomized, double-blind study (Akershus Study). Epilepsia 2008; 49: 455-463.

[131] Gabriël S, Blocher J, Dorny P, Abatih E, Schmutzhard E, Ombay M, Mathias B, Winkler AS. Added value of antigen ELISA in the diagnosis of neurocysticercosis in resource poor settings. PLoS Neglected Tropical Diseases 2012, in print

[132] Nakano A, Yamasaki R, Miyazaki S, Horiuchi N, Kunishige M, Mitsui T. Beneficial effect of steroid pulse therapy on acute viral encephalitis. European Neurology 2003; 50: 225-229.

[133] Ramachandran TS 2008. Tuberculous meningitis. http://emedicine.medscape.com/article/1166190-overview Last accessed August 2012

[134] Garcia HH, Pretell EJ, Gilman RH, Martinez SM, Moulton LH, Del Brutto OH, Herrera G, Evans CA, Gonzalez AE; Cysticercosis Working Group in Peru. A trial of antiparasitic treatment to reduce the rate of seizures due to cerebral cysticercosis. New England Journal of Medicine 2004; 350: 249-258.

[135] Das K, Mondal GP, Banerjee M, Mukherjee BB, Singh OP. Role of antiparasitic therapy for seizures and resolution of lesions in neurocysticercosis patients: an 8 year randomized study. Journal of Clinical Neuroscience 2007; 14: 1172-1177. 